\title{
Los planes de ordenamiento territorial departamental: beneficios y riesgos de un instrumento clave para la ordenación del territorio en Colombia
}

Héctor Santaella Quintero

\section{RESUMEN}

Con base en las facultades que les reconoce la Ley 1454 de 2011 a los departamentos, con el apoyo del Gobierno nacional, estas entidades territoriales se preparan para la expedición de planes departamentales de ordenamiento territorial. Con ello se agrega una pieza fundamental a nuestro esquema de ordenación del territorio, hasta hoy construido a partir de una visión esencialmente municipal. No obstante, pese a la importancia de este paso (por los beneficios que comporta), la total ausencia de un régimen legal que enmarque y oriente el ejercicio de esta competencia origina riesgos notables para la legalidad de las actuaciones que se desarrollan, así como para la autonomía

1 Abogado y magíster en Derecho Administrativo de la Universidad Externado de Colombia Bogotá, Colombia. Doctor en Derecho por la Universidad Autónoma de Madrid, Madrid, España. Profesor del Departamento de Derecho Administrativo de la Universidad Externado de Colombia, Bogotá, Colombia. Correo-e: hector.santaella@uexternado.edu.co. Fecha de recepción: 15 de febrero de 2018. Fecha de modificación: 20 de marzo de 2018. Fecha de aceptación: 10 de mayo de 2018. Para citar el artículo: Santaella Quintero, HÉCTOR, "Los planes de ordenamiento territorial departamental: beneficios y riesgos de un instrumento clave para la ordenación del territorio en Colombia", Revista digital de Derecho Administrativo, Universidad Externado de Colombia, n. ${ }^{\circ}$ 20, 2018, pp. 57-94. DOI: https:// doi.org/10.18601/21452946.n20.05. 
local y la participación ciudadana en la toma de estas decisiones. El artículo explora estos asuntos.

Palabras clave: Ordenación del territorio, Ordenamiento territorial, Planes de ordenamiento territorial, Planes departamentales de ordenamiento territorial, Autonomía local en la ordenación del territorio, Participación ciudadana.

\title{
Departmental Plans of Land Use Planning: Benefits and Risks of a Key Instrument in Colombian Land Use Planning
}

\begin{abstract}
Based on the powers granted by the Law 1454 of 2011 and supported by the National Government, the departments are currently working on the enactment of instruments of land use planning in a departmental scale. They will complete the Colombian land planning system, until now constructed essentially from a local point of view. Despite the benefits of this development, the total absence of a legal frame to guide and regulate the exercise of this power appears to be very problematic. This paper shows serious doubts pertaining to the legality of the projected departmental instruments before examining how these instruments may affect local autonomy and citizen participation in land use planning decisions.
\end{abstract}

Keywords: Land Use Planning, Local Plans of Land Use Planning, Departmental Plans of Land Use Planning, Local Autonomy, Citizen Participation.

\section{INTRODUCCIÓN}

A pesar de la generalizada sensación de insatisfacción dejada por los contenidos insuficientes de la Ley Orgánica de Ordenamiento Territorial (LOOT) en relación con el perfeccionamiento del modelo territorial nacional o la profundización de la descentralización ${ }^{2}$, esta ley realizó un aporte fundamental en el

2 La doctrina nacional ha realizado un balance más bien desfavorable de la LOOT. Al respecto, véase los comentarios de Paula Robledo Silva, "La Ley Orgánica de Ordenamiento Territorial: ¿Una asignatura pendiente?", Derecho procesal administrativo, modernización del Estado y territorio. Estudios en homenaje a Augusto Hernández Becerra, Bogotá: Ibáñez, 2014, pp. 946 y ss.; VANESSA Suelt Cock, "Un nuevo paradigma del estado unitario: la asimetría territorial y los esquemas de coordinación", Universitas, n. ${ }^{\circ}$ 127, 2013, pp. 328-329, LiLIANA EsTUPIÑán ACHURY. Desequilibrios territoriales. Estudio sobre la descentralización y el ordenamiento territorial colombiano. Una mirada desde el nivel intermedio de Gobierno, Bogotá: Doctrina y Ley - Universidad del 
campo de la ordenación del territorio. En efecto, pese a no ser este, en estricto sentido, uno de los cometidos constitucionales centrales o explícitos de esta normativa $^{3}$, el legislador, presa de la confusión (habitual entre nosotros ${ }^{4}$ ) entre ordenación del territorio y organización territorial (generada por la ambigüedad y polisemia de la expresión "ordenamiento territorial" empleada por el propio Constituyente), y atendiendo a una decisión de la Corte Constitucional del año 2000, acabó por ocuparse tangencialmente del asunto particular de la ordenación física del espacio en una escala supralocal y realizar con ello una contribución significativa en este campo. Así, no obstante su carácter de norma de vocación general (i. e. no sectorial) estructural dentro de la organización del modelo territorial y el reparto de competencias interadministrativas al interior del sistema normativo colombiano, la LOOT, en su artículo 29, definió algunas competencias cruciales para la consolidación del esquema de ordenación del territorio en Colombia. En esencia, reconoció el papel que en esta materia corresponde a la nación y a los departamentos, primordialmente a cargo de los entes locales desde la sentencia C-795 de 2000 de la Corte Constitucional ${ }^{5}$.

Rosario, 2012, pp. 287 y ss.; Naidú DuQue CanTe. "Particularidades de la Ley Orgánica de Ordenamiento Territorial", Análisis Político, vol. 25, n. ${ }^{\circ} 76,2012$, ab initio (sp). Disponible en línea https://revistas.unal.edu.co/index.php/anpol/article/view/43501/44784.

3 Según ha sido señalado por la jurisprudencia constitucional, a la luz de los preceptos constitucionales que definen sus contenidos, la denominada "reserva de ley orgánica en materia de ordenamiento territorial", esto es, aquellos asuntos frente a los cuales inexorablemente debe pronunciarse la LOOT, son los relativos a: a) la estructura territorial y la organización de los poderes públicos en el territorio; b) los mecanismos de participación para definir la incorporación y pertenencia a una división territorial ${ }_{i}$ y c) la asignación de competencias normativas y no normativas de las entidades territoriales y la resolución de los conflictos competenciales con la Nación (véase sentencia C-489 de 2012 de la Corte Constitucional).

4 Resaltan la falta de diferenciación o confusión terminológica que se observa en el derecho colombiano entre organización territorial y ordenación del territorio, en autores como Pedro Pablo Morcillo Dosman, Derecho urbanístico colombiano. Historia, derecho y gestión, Bogotá: Temis, 2007, pp. 125-126; LiLIANA Estupiñán ACHURY, op. cit., pp. 286-287; o FeLIPE ARBouin GÓmEz. "Derecho urbanístico y desarrollo territorial colombiano. Evolución desde la colonia hasta nuestros días", en Revista Universitas, n. ${ }^{\circ} 124,2012$, pp. 38-39.

5 Debe señalarse que originalmente la Ley 388 de 1997 había previsto en su artículo 7, en términos muy similares a los del actual artículo 29 de la LOOT, un arreglo competencial que implicaba directamente a la nación, los departamentos y las áreas metropolitanas, junto con los municipios, en el desarrollo de la planeación territorial espacial. Es decir, el modelo inicial de OT concebido por el legislador para nuestro país partía de una articulación de los diferentes niveles administrativos del Estado, que se concretaba en el reconocimiento de competencias directas para cada uno de ellos. No obstante, dicho precepto fue declarado inexequible por la Corte Constitucional en la sentencia C-795 de 2000, por considerar que tal determinación suponía una intromisión del legislador ordinario en el ámbito de la reserva de ley especial prevista por el artículo 288 de la Constitución, según el cual le corresponde a la LOOT establecer "la distribución de competencias entre la Nación y las entidades territoriales". Una comprensión, sin duda, demasiado rígida de dicha reserva 
Con esta determinación dotó de una dimensión supralocal al esquema puesto en práctica después de la decisión del juez constitucional, adoptada al poco tiempo de haber entrado en vigencia la Ley 388 de 1997 (LDU), concretado en la expedición de planes de ordenamiento territorial (РОT) por municipios y distritos. Con ello, el legislador complementó y completó (de nuevo, si se quiere, pero ahora por medio de una ley orgánica, tal como lo dispuso en su momento la Corte Constitucional) este modelo.

En efecto, luego de una lenta evolución ${ }^{6}$, el legislador colombiano optó en 1997, con la expedición de la LDU, por un esquema de ordenación territorial y urbanística que hizo de estas dos tareas una responsabilidad que, por terminar

de ley, que de haberse seguido a píe juntillas en todos los casos habría supuesto la inconstitucionalidad de prácticamente cualquier ley sectorial que otorgue competencias a los entes territoriales $y$, por tanto, instrumente un arreglo competencial entre los distintos niveles administrativos del Estado sin la previa cobertura de la recién expedida LOOT (los casos abundan: las leyes 99 de 1993, 100 de 1993, 142 de 1994 o 397 de 1997 son algunos ejemplos conspicuos de ello). En últimas, como lo señalan los magistrados Naranjo y Beltrán en su salvamento de voto frente a la decisión que se comenta, "cada una de las leyes orgánicas de que trata el artículo 151 Superior, debe ser objeto de una detallada y cuidadosa limitación, en el entendido de que una interpretación muy amplia del ámbito que se reserva a las leyes orgánicas, podría vaciar la competencia del legislador ordinario y, en esa medida, restringir el principio democrático que orienta el Estado Social de Derecho que nos rige". Por esta razón, se impone una interpretación restrictiva de cuáles son los contenidos propios de la ley orgánica, que ofrezca criterios ciertos al legislador sobre cuándo se está ante un contenido de esta índole. Algo que no se hizo en este fallo (pues, como lo afirman los magistrados disidentes en su voto particular, es muy discutible que el artículo 7 de la Ley 388 de 1997 forme parte de ese núcleo temático) y que tampoco la jurisprudencia constitucional ha logrado hacer con éxito. La declaratoria reciente de inexequibilidad del artículo 37 del Código de Minas (Ley 685 de 2001) en la sentencia C-273 de 2016, por estimar que dicho precepto estaba amparado por la reserva de la Ley Orgánica de Ordenamiento Territorial, es la mejor muestra de ello. En este fallo, dando un nuevo salto en su zigzagueante jurisprudencia en esta materia, la Corte planteó que "las garantías institucionales se ven reforzadas en la medida en que el Legislador intervenga sobre competencias atribuidas constitucionalmente a las entidades territoriales. Más aún, las garantías institucionales de orden procedimental, como la reserva de ley orgánica, adquieren especial relevancia en la medida en que concurran competencias que tengan un claro fundamento constitucional. En tales casos adquieren especial importancia la estabilidad, transparencia y el fortalecimiento democrático que otorga la reserva de ley orgánica al proceso de toma de decisiones al interior del Congreso". Y estimó que en el caso del artículo 37 del Código de Minas, que prohibía a las entidades de los órdenes "regional, seccional o local" excluir temporal o permanentemente la actividad minera, cobijando expresamente a los POT, se "afecta de manera directa y definitiva la competencia de las entidades territoriales para llevar a cabo el ordenamiento de sus respectivos territorios. Por lo tanto, es una decisión que afecta bienes jurídicos de especial importancia constitucional y, en esa medida, está sujeta a reserva de ley orgánica". Por ende, concluye la Corte (con base en su nuevo rasero), dicha disposición debía haber sido adoptada por una norma legal orgánica. La ausencia de criterios claros y ciertos es, pues, notable.

6 Véase María Mercedes Maldonado Copello, "El proceso de construcción del sistema urbanístico colombiano: entre reforma urbana y ordenamiento territorial", en Direito 
fundamentalmente en manos de las municipalidades, acabó siendo la misma (es decir, una única tarea o competencia), proyectada como un ámbito privilegiado para el ejercicio de autonomía local ${ }^{7}$. El legislativo fusionó así dos competencias habitualmente separadas (la de ordenación del territorio y la de ordenación urbanística ${ }^{8}$ ) y confió su ejercicio al municipio. El sistema colombiano implantado se apartó entonces de la línea que se observa en otros ordenamientos (v.gr. Alemania, Austria, España, Francia, Italia, Bélgica o Suiza) en los que se trata de competencias separadas, aunque concurrenciales y forzosamente coordinadas. El régimen legal establecido se basa en la definición de algunos criterios sustanciales y de un marco procedimental para el desarrollo de la competencia por parte de los entes locales, con lo cual se instauró un esquema edificado sobre la base de una elevada discrecionalidad del municipio ${ }^{9}$, enmarcada por una programación legal esencialmente finalista

Urbanístico. Estudos brasileiros e internacionais, Belo Horizonte: Editora Del Rey - Lincoln Institute of Land Policy, 2006, pp. 26 y ss.

7 Así lo establece la Ley 388 de 1997 en su artículo 1.2, que declara como objetivo de esta norma "El establecimiento de los mecanismos que permitan al municipio, en ejercicio de su autonomía, promover el ordenamiento de su territorio, el uso equitativo y racional del suelo, la preservación y defensa del patrimonio ecológico y cultural localizado en su ámbito territorial y la prevención de desastres en asentamientos de alto riesgo, así como la ejecución de acciones urbanísticas eficientes". Del mismo modo, la jurisprudencia constitucional, con base en lo previsto por la Constitución en torno a la facultad de los concejos para reglamentar los usos del suelo, ha estimado que "la trascendencia de la función asignada a concejos distritales y municipales por los artículos 311 y 313 numeral 7 [...] es que en un Estado unitario, con autonomía de sus entidades territoriales y que adopta como pilar fundamental la participación de sus habitantes en las decisiones que los afectan, se entienda el papel de estas corporaciones como un elemento identificador de la esencia y determinador del desarrollo práctico del régimen territorial previsto por la Constitución". Cfr. Corte Constitucional, sentencia C-123 de 2014. En sentido similar, véase la sentencia C-298 de 2016 de la misma corporación. También véase Héctor Santaella Quintero, "El autogobierno del territorio: ¿Un contenido esencial de la autonomía territorial?", en Derecho procesal administrativo, modernización del Estado y territorio. Estudios en bomenaje a Augusto Hernández Becerra, Bogotá: Ibáñez, 2014, pp. 767 y ss.

8 Analiza esta diferencia y ofrece criterios para su aislamiento y separación JORGE AGUDO GONZÁlEZ, "La formalización jurídico administrativa de la ordenación del territorio en España", Teoría y práctica para una ordenación racional del territorio, Madrid: Síntesis, 2010, pp. 48 y ss. También Luciano Parejo Alfonso, "La ordenación territorial y urbanísticas y el gobierno de la ciudad en el estado territorialmente descentralizado", Revista digital de Derecho Administrativo, n. ${ }^{\circ} 7,2012$, pp. 64 y ss.

9 Para Santofimio Gamboa, esta constituye "el más inmenso poder discrecional que el ordenamiento ha depositado en las autoridades públicas municipales". Cfr. Jaime OrLando Santofimio Gamboa, "Estudio introductorio. Características del derecho urbanístico colombiano", Derecho urbanístico. Legislación y jurisprudencia, Bogotá: Universidad Externado de Colombia, 2004, p. 42. Ello, en todo caso, armoniza con la tendencia que se observa de manera generalizada de revestir a las autoridades de planificación urbanística de un alto grado de discrecionalidad. Así, por ejemplo, para Baño León la discrecionalidad es "Lo propio de la ordenación urbanística en un régimen de planificación pública". Cfr. José 
y procedimental ${ }^{10}$, básicamente condicionada por unos determinantes dictados por órganos administrativos a cargo de intereses supramunicipales ${ }^{11}$. Esto último, como fórmula para asegurar la coordinación de las decisiones locales con los intereses de la nación, las regiones y los departamentos que confluyen sobre el territorio ordenado ${ }^{12}$.

Ahora bien, este esquema resulta complementado por las atribuciones competenciales del artículo 29 de la LOOT a favor de la nación y los departamentos, toda vez que, como se ha indicado por la doctrina, la ausencia de una dimensión regional de la ordenación del territorio resultaba problemática, puesto que hacía de la ordenación "un mapa de fragmentos" ${ }^{13}$. De especial interés resulta, entonces, lo previsto por el artículo 29.2 de la LOOT a favor de los entes

María Baño León, Derecho urbanístico común, Madrid: Iustel, 2009, p. 237. En sentido similar, José María Rodríguez De SANTiago, La ponderación de bienes e intereses en el Derecho administrativo, Madrid - Barcelona: Marcial Pons, 2000, p. 34. También Eberhard Schmidt-Assmann, La teoría general del derecho administrativo como sistema, Madrid - Barcelona: Marcial Pons, 2003, p. 215.

10 Frente a la imposibilidad del legislador de llevar a cabo una programación material detallada de la decisión administrativa en este campo, la ley configura sus fines y estatuye un procedimiento apto para condicionar e incidir de manera sustantiva sobre la determinación final que se adopte. Ello, con un doble propósito: de un lado, compensar el déficit de programación material que resulta de la complejidad de la planificación y ordenación del territorio; de otro, dar cumplimiento al mandato que la Constitución impone de manera general al legislador de dirigir normativamente las actuaciones administrativas. Cfr. JosÉ María Rodríguez de Santiago, Metodología del derecho administrativo. Reglas de racionalidad para la adopción y el control de la decisión administrativa, Madrid: Marcial Pons, 2016, pp. 26 y ss.

11 Según lo reglado por el artículo 10 de la Ley 388 de 1997, los determinantes "constituyen normas de superior jerarquía", que deben ser considerados por los municipios al formular y adoptar sus POT, y emanan de las autoridades ambientales, de protección del patrimonio histórico cultural, de infraestructura en materia de vías, puertos, aeropuertos y servicios públicos domiciliarios, así como de las autoridades metropolitanas. En adición a estos determinantes, el legislador ha definido otros, establecido en leyes sectoriales, como la sujeción a los instrumentos de ordenación del suelo rural definidos por la UPR (artículo 3.9 de la Ley 1551 de 2012) o al Plan Nacional de Gestión del Riesgo (artículo 41 de la Ley 1523 de 2012). Al respecto, véase Héctor Santaella Quintero, "Urbanismo y minería: tensiones y conflictos sobre los usos del suelo en el territorio municipal", Revista de Derecho Administrativo Económico, n. ${ }^{\circ} 19,2014$, pp. 102 y ss.

12 En relación con el papel que cumplen los determinantes en la ordenación del territorio a cargo de los entes locales, véase Héctor Santaella Quintero, “Un territorio y tres modelos de gestión: análisis de la necesidad de armonizar y constitucionalizar las competencias urbanísticas, ambientales y mineras sobre el territorio", Minería y desarrollo. Historia y gobierno del territorio minero, t. 5, Bogotá: Universidad Externado de Colombia, 2016, pp. 174 y ss. También Luis FernANDo HeRnández BetanCur. "Planificación territorial para el desarrollo sostenible", en Lecturas sobre derecho del medio ambiente, t. XII, Bogotá: Universidad Externado de Colombia, 2012, p. 267.

13 Juan Carlos del Castillo Daza, "Ordenamiento territorial y ordenamiento ambiental", Problemática jurídico-ambiental de los centros urbanos, Bogotá: Universidad Externado de Colombia, 2002, p. 98. 
departamentales, ya que les reconoce competencia para: a) "Establecer directrices y orientaciones para el ordenamiento de la totalidad o porciones específicas de su territorio, especialmente en áreas de conurbación"114, b) "Definir las políticas de asentamientos poblacionales y centros urbanos, de manera que facilite el desarrollo de su territorio"15, c) "Orientar la localización de la infraestructura físico-social de manera que se aprovechen las ventajas competitivas regionales y se promueva la equidad en el desarrollo municipal"16, y d) "articular sus políticas, directrices y estrategias de ordenamiento físico-territorial con los planes, programas, proyectos y actuaciones sobre el territorio, mediante la adopción de planes de ordenamiento para la totalidad o porciones específicas de su territorio"17. Como destaca el Departamento Administrativo Nacional de Planeación (DNP), a partir de estas facultades los departamentos podrán

concertar acuerdos para el desarrollo territorial, establecer las líneas estratégicas de trabajo conjunto con los municipios, promover procesos de desarrollo territorial articulados, orientar los procesos de ordenamiento territorial supramunicipal, promover actuaciones de interés departamental o supramunicipal y gestionar proyectos de impacto regional que beneficien a más de un municipio de su jurisdicción ${ }^{18}$.

Es, pues, con base en estas atribuciones competenciales que se ha comenzado a hablar de los planes de ordenamiento territorial departamental (POD) como una nueva pieza del modelo de ordenación del territorio en Colombia. Y aun cuando se trata de instrumentos in fieri, la expectación los rodea y su figuración se acrecienta conforme los departamentos comienzan a hacer uso de sus facultades $^{19}$. No es para menos si se tiene en cuenta que con ellos se restablece el sistema originalmente concebido por el legislador de 1997, reintroduciendo

18 Departamento Administrativo Nacional de Planeación, Balance sobre los avances en el diseño e implementación de lineamientos de ordenamiento territorial departamental que ban sido llevados a cabo en el país, Bogotá, 2013, p. 11. Disponible en línea https://colaboracion.dnp.gov.co/CDT/Desarrollo\%20Territorial/Balance\%20procesos\%20de\%20Ordenamiento\%20Territorial\%20 Departamental.pdf.

19 Departamentos como el Valle del Cauca o Caldas ya han iniciado la tramitación de estos instrumentos. Sobre los avances del POD del Valle del Cauca, véase la página web: http:// www.valledelcauca.gov.co/publicaciones. php? $\mathrm{id}=36385 \& \mathrm{dPrint}=1$; respecto del POD del departamento de Caldas, véase la página web: https://es.unhabitat.org/caldas-tendraprimer-plan-de-ordenamiento-territorial-departamental-en-colombia/. El Departamento Administrativo Nacional de Planeación (DNP), por su parte, ha promovido e impulsado estas figuras con la expedición de documentos orientadores y la realización de talleres que buscan apoyar estas figuras. Véase la página web: https://www.dnp.gov.co/programas/desarrollo-territorial/secretaria-tecnica-de-la-comision-de-ordenamiento-territorial/ Paginas/directrices-departamentales-de-ordenamiento-territorial.aspx. 
un elemento que ofrece una perspectiva supramunicipal, ausente por muchos años como consecuencia de la temprana decisión del juez constitucional que impidió que la previsión legal original tuviera efectos relevantes en la práctica ${ }^{20}$. No en vano el artículo 29 de la LOOT reproduce en términos prácticamente idénticos el artículo 7 de la LDU, declarado inexequible por la Corte Constitucional. Con todo, su adopción no está exenta de cuestionamientos. Dado el estado actual de la legislación en la materia, desprovista de un auténtico régimen que discipline (material y procedimentalmente) el ejercicio de la competencia otorgada por la LOOT, surgen diferentes reparos a su trámite y aprobación. El presente escrito expone, entonces, cómo si bien existen razones por las cuales la ordenación departamental del territorio constituye un avance plausible en el proceso de construcción y consolidación del modelo de ordenación del territorio (1), hay también serias objeciones y reservas frente a la expedición de esta clase de instrumentos (2). El texto cierra con algunos comentarios y reflexiones finales sobre el asunto examinado (3).

\section{LA ORDENACIÓN DEPARTAMENTAL DEL TERRITORIO COMO AVANCE EN EL PROCESO DE CONSTRUCCIÓN Y CONSOLIDACIÓN DEL MODELO DE ORDENACIÓN TERRITORIAL EN COLOMBIA}

Definidos por el Acuerdo 10 de 2016 de la COT como el "Instrumento para el ordenamiento del territorio departamental, que comprende un conjunto de herramientas articuladas y armonizadas, tales como modelos, directrices, políticas, estrategias, planes, programas y proyectos de impacto territorial supramunicipal, con una perspectiva de largo plazo"21, los POD están llamados a brindar al sistema de ordenación territorial en Colombia la perspectiva supralocal que se echaba de menos. Algo esencial para asegurar mayor consistencia y consonancia de las determinaciones que adoptan los municipios y distritos en sus POT, promover esquemas más eficientes y sostenibles de aprovechamiento de los recursos naturales, garantizar mayor cohesión de los territorios interdepartamentales, imprimirles mayor competitividad y desarrollo, y propiciar economías de escala en la ejecución de infraestructuras, equipamientos, programas sociales y prestación de servicios públicos.

20 Por su pronta desaparición del ordenamiento jurídico, los departamentos no lograron hacer uso efectivo de dicha competencia. Una excepción fue el departamento del Huila, que en el año 2000 formuló y adoptó mediante la Ordenanza 78 el Plan de Ordenamiento Territorial del Departamento del Huila.

21 Artículo 1.1. 
No se trata, naturalmente, de abjurar de las bondades de la ordenación local del territorio ${ }^{22}$, impuesta entre nosotros por expresa disposición constitucional (artículo 313.9) ${ }^{23}$, sino de examinar las razones por las cuales la incorporación de los POD dentro del sistema nacional de ordenación del territorio refuerza el modelo imperante. Al menos dos razones parecen respaldar esta idea: de un lado, las ventajas que para un ejercicio cabal de ordenación del territorio ofrece contar con una perspectiva supramunicipal (1.1); y de otro, las mejores condiciones que tiene el departamento para coordinar las decisiones y los actores que confluyen en el territorio, como un aspecto esencial de la OT (1.2).

\subsection{LA NECESARIA VISIÓN SUPRALOCAL DEL TERRITORIO}

Si se parte de la base que la OT se define, fundamentalmente, "por la voluntad, expresada desde los poderes públicos, de introducir un componente de racionalidad en la disposición de los elementos que conforman el orden territorial, guiando el sentido de las transformaciones que todo el territorio debe inevitablemente experimentar ${ }^{\prime 24}$, la escala territorial que se maneje (municipal, departamental, regional o nacional) puede resultar relativa. No obstante, tanto por su origen y evolución histórica, como por sus fines y conceptualización actual, puede advertirse que progresivamente la OT se ha perfilado como una política y una competencia de planificación del espacio ejercida idealmente a una escala intermedia.

Así, desde una perspectiva histórica, debe tenerse en cuenta que la OT surge en el primer tramo del siglo XX con la finalidad de hacer frente a los efectos

22 Las ventajas de este modelo son evidentes, tanto en términos de fortalecimiento de la descentralización y de las notables posibilidades que brinda para el desarrollo del principio de autonomía, como de profundización del sistema democrático, vitalizado por obra de la mayor y más vigorosa participación ciudadana en las decisiones que afectan su entorno inmediato, lo mismo que por el más efectivo control que se puede realizar por la ciudadanía sobre los gobernantes y la ejecución de las medidas contenidas en el POT. Lo anterior, además de que el "esquema de decisión de abajo a arriba", como de manera gráfica lo denomina la Corte Constitucional en la sentencia T-537 de 2013, no solo imprime en general mayor legitimidad a las decisiones del planeamiento y crea mejores condiciones para su efectividad y estabilidad, sino que también hace posible, como es señalado por Agudelo Patiño, contar para este proceso con el conocimiento del territorio que tiene la comunidad en sus prácticas tradicionales de producción y en su memoria, que posee "datos útiles para el conocimiento científico del territorio en cuestión". Cfr. LuIs CaRLOS Agudelo Patiño, La ciudad sostenible. Dependencia ecológica y relaciones regionales. Un estudio de caso en el área metropolitana de Medellín, Medellín: Universidad Nacional de Colombia, Sede Medellín, 2010, p. 107.

23 Véase Héctor Santaella Quintero, "El autogobierno del...", op. cit., pp. 764 y ss.

24 Luis Galiana y Julio Vinuesa, "Definición y evolución del concepto y de su práctica", Teoría y práctica para una ordenación racional del territorio, Madrid: Editorial Síntesis, 2010, p. 21. 
negativos de los procesos de urbanización e industrialización que se proyectan más allá de las urbes, a una escala regional ${ }^{25}$. Aun cuando su enfoque era originalmente variable (más centrado a la ordenación física espacial en países como Alemania y Holanda, a la corrección de los desequilibrios territoriales $-\mathrm{y}$, por lo tanto, a la planificación económica y social- en Francia, Italia o Reino Unido o a ambas cosas en los EE.UuU. ${ }^{26}{ }^{27}$ ), en los años setenta del siglo pasado se impregna de la preocupación por la protección del medio ambiente y los recursos naturales, dejando atrás los enfoques parciales de la planificación sectorial. Se asume con ello una perspectiva más amplia e integral de su cometido, centrado en asegurar una estructuración del territorio apta para consolidar el desarrollo socioeconómico sostenible de un territorio, la calidad de vida de sus habitantes y la corrección de los desequilibrios regionales y territoriales ${ }^{28}$. En el curso de este proceso, la escala territorial intermedia se impone.

Lo anterior se ve reflejado en su caracterización en instrumentos internacionales. La Carta Europea de Ordenación del Territorio, del 20 de mayo de 1983, por ejemplo, define la OT como "una política concebida como un enfoque interdisciplinario y global cuyo objetivo es un desarrollo equilibrado de las regiones y la organización física del espacio según un concepto rector". Y a ella se asignan objetivos en materia de desarrollo equilibrado de las regiones, mejoramiento de la calidad de vida, protección del entorno, gestión responsable de los recursos naturales y utilización racional del territorio ${ }^{29}$. También permite ratificar su vinculación con instancias supralocales la definición doctrinal de su doble naturaleza, de política pública y competencia administrativa específica (esta última al servicio de la primera), singularizada por su carácter transversal y vocación integradora de las diferentes determinaciones que se adoptan sobre el territorio; las cuales hacen patente que "Más allá de la regulación del régimen del suelo desde una perspectiva meramente local propia del urbanismo, la OT asume una escala supramunicipal a nivel subregional y/o

26 Es célebre el caso de la Tennessee Valley Authority, creada por ley en 1933 con el fin de utilizar integralmente el valle del río Tennessee, que discurre por varios estados, por medio del desarrollo de programas y acciones en materia de desarrollo energético, control de inundaciones, manejo de suelos y recursos naturales, desarrollo rural, reforestación, diversificación industrial e, incluso, planificación de ciudades. Cfr. Fernando López Ramón, Introducción al derecho urbanístico, 4. ${ }^{a}$ edición, Madrid: Marcial Pons, 2013, p. 68.

27 En América Latina, explica Massiris, desde mediados del siglo pasado, la OT se ha proyectó, inicialmente, en tres direcciones: el desarrollo integrado de cuencas hidrográficas, las políticas de regionalización y los llamados polos de desarrollo o polos de crecimiento. Luego se le añadirían otros instrumentos como la planificación de los usos del suelo y la descentralización. Cfr. ÁnGEL MASSIRIS CABEZAS, "Políticas latinoamericanas de ordenamiento territorial. Realidad y desafíos", Procesos de ordenamiento en América Latina y Colombia, Bogotá: Universidad Nacional de Colombia, 2012, pp. 14 y ss.

28 Luis Galiana y Julio Vinuesa, op. cit., pp. 21 y ss.

29 Carta Europea de Ordenación del Territorio, 20 de mayo de 1983 
regional (o transnacional) ${ }^{\prime \prime 30}$. Múltiples razones, en fin, para convenir que en atención a su esencia, finalidades y misión, un genuino ejercicio de OT precisa de una mirada supramunicipal del territorio. Ordenar los territorios municipales resulta crucial, pero no basta para cumplir los más elevados cometidos de la OT.

No es casual, entonces, que a nivel comparado OT y ordenación urbanística constituyan competencias y disciplinas separadas. Así, aun cuando en Colombia la LDU empleó la expresión "ordenamiento del territorio"31, a la que asignó unos fines y un objeto muy similares a los de la $\mathrm{OT}^{32}$, hay motivos para dudar sobre si lo que reguló entonces el legislador no corresponde más a una función de ordenación urbanística del territorio municipal (en una comprensión amplia y moderna de esta disciplina, desde luego) que a una auténtica $\mathrm{OT}^{33}$.

Sostener que la LDU se centra más en la ordenación urbanística del territorio que en una genuina OT implica tener en cuenta que, a pesar de la proximidad que existe entre una y otra disciplina, hay diferencias claras entre ellas: en primer lugar, el diferente ámbito de cobertura de cada responsabilidad, toda vez que la perspectiva local propia del urbanismo diverge de la mayor amplitud de miras (necesariamente supralocal, habitualmente regional) de la ordenación del territorio ${ }^{34}$. En segundo lugar, sus fines son disímiles, ya que aun cuando desde una óptica general una y otra buscan "la organización del suelo y el espacio más adecuada para la efectividad y plenitud en la vida individual y

31 Véase, por ejemplo, los artículos 1.2, 1.4, 2, 3, 5, 6, 8 y 9 de LDU.

32 Véase los artículos 3 y 6 de LDu.

33 Determinar el objeto específico de la LDu no es sencillo. Las lecturas que se han hecho de su texto son diversas. Así, por ejemplo, debido a su sesgo urbano, que apenas si toma en consideración al suelo rural (a pesar de ser objeto formal de su ordenación), para brindar en cambio una atención especial y detallada al suelo urbano, Agudelo Patiño califica a la LDU como una ley más "de administración del suelo urbano, y no de una ley de ordenamiento territorial completa". Véase Luis Carlos Agudelo Patiño, op. cit., p. 113. Hay, asimismo, voces autorizadas que equiparan entre nosotros la ordenación urbanística y la OT, prescindiendo de esta distinción. En este sentido, véase, por ejemplo, Pedro Pablo Morcillo Dosman, op. cit., p. 126; o Jorge IvÁn RinCÓN CóRdoba, Planes de ordenamiento territorial, propiedad y medio ambiente, Bogotá: Universidad Externado de Colombia, 2012, p. 42. El DNP, por su parte, advierte sobre el hecho que en Colombia "no existe una definición unívoca del OT, respecto al cual se identifican diferentes enfoques y acepciones. Por ejemplo, en la Ley 99 de 1993 se hace referencia al ordenamiento desde el punto de vista ambiental ${ }_{i}$ en la Ley 388 de 1997 se aborda el tema desde la perspectiva físico-espacial, en la Ley 715 de 2001 y otras leyes sectoriales se hace referencia a la distribución de competencias y recursos [... y y en los proyectos de la Ley Orgánica de Ordenamiento Territorial prima la perspectiva de la organización político-administrativa en el territorio". Cfr. Departamento Administrativo de Planeación Territorial. Notas sobre el ordenamiento territorial y los proyectos de ley orgánica de ordenamiento territorial (Documento de Trabajo), 2007 (s.n.). Citado por LiLIANA ESTUPIÑÁN ACHURY, op.. cit., p. 287.

34 Cfr. Jorge Agudo González, op. cit., pp. 46 y ss. También Domingo Gómez Orea, Ordenación territorial, Madrid: Ediciones Mundi-Prensa - Editorial Agrícola Española, 2002, p. 39. 
colectiva de los valores constitucionales ${ }^{1 / 35}$, la OT no solo persigue objetivos de calidad de vida y crecimiento ordenado de la ciudad (objetivos propios del urbanismo ${ }^{36}$ ), sino también promover un desarrollo competitivo, sostenible y equilibrado de los distintos territorios que conforman una región, así como la cohesión económica y social de las distintas regiones que conforman un $E_{s t a d o}{ }^{37}$. Y aun cuando su objeto es afín, dado que una y otra hacen referencia a la responsabilidad estatal por la racionalización y la ordenación de la utilización de un espacio físico ${ }^{38}$, la amplitud y heterogeneidad de intereses comprendidos en uno y otro caso permite apuntalar la distinción planteada ${ }^{39}$ : mientras que la disciplina urbanística se articula fundamentalmente en torno a los intereses locales de la ciudad, la OT comprende intereses supralocales, en tanto se da en un espacio social y físico mayor.

La ausencia de la perspectiva supramunicipal resultaba inconveniente para el esquema instaurado en Colombia por la LDU por diferentes razones. La escala más reducida que tiene el municipio del espacio que se ordena genera un fraccionamiento del territorio, "con serias implicaciones en el manejo de los elementos estructurantes de la base natural (ecosistemas montañosos, cuencas abastecedoras, fallas geológicas) y de la infraestructura, así como de los procesos y relaciones productivas, sociales y culturales" ${ }^{\prime \prime 4}$. La "insularidad de los POT $^{\prime \prime 4}$ lleva a que, por ejemplo, en la clasificación, delimitación y ordenación de suelos rurales, suburbano y de expansión urbana, se ignoren dinámicas regionales o subregionales con incidencia fuerte sobre el territorio ${ }^{42}$. Consciente de esta circunstancia, el legislador, en el apartado final del artículo 6 de la LDU, impuso el mandato de tener en cuenta "las relaciones intermunicipales, metropolitanas y regionales". Pese a ello, las limitaciones para concebir el territorio y todo

Luciano Parejo Alfonso, "La ordenación territorial...", op. cit., p. 67.

36 Etimológicamente, como lo reseña el DLE, la voz "urbanismo" se compone de dos partículas: urbano e ismo, lo cual remite a la primera acepción de este sustantivo: "Conjunto de conocimientos relacionados con la planificación y desarrollo de las ciudades". Cfr. http://dle.rae.es/?id=b8IcS7s.

37 Así, por ejemplo, la Estrategia Territorial Europea, "Hacia un desarrollo equilibrado y sostenible del territorio de la Unión Europea" (1999), tiene como norte la armonización de tres objetivos fundamentales: a) el desarrollo competitivo y equilibrado de los territorios de la Unión Europea ${ }_{i}$ b) la conservación de sus ecosistemas y recursos naturales, así como de su patrimonio cultural ${ }_{i}$ y c) la cohesión económica y social de todas sus regiones.

38 Luciano Parejo Alfonso, "La ordenación territorial y...", op. cit., p. 67.

39 Ibíd.

40 Juana Mariño Drews, "Territorio... ¿Cuál territorio? Elementos para una investigación", Evaluación y perspectivas del Código Nacional de Recursos Naturales de Colombia en sus 30 años de vigencia, Bogotá: Universidad Externado de Colombia, 2004, p. 455.

41 Luis AníbAl VélEz ResTREPO, "La perspectiva ambiental en el plan de ordenamiento territorial del municipio", Los planes de ordenamiento territorial municipal en Antioquia, Medellín: Universidad Nacional de Colombia, 2013, p. 13. 
lo que él engloba en su dimensión y complejidad plenas, más allá de las jurisdicciones locales, se han hecho manifiestas en la práctica. Bien por debilidad institucional, carencia de información, problemas de coordinación o falta de voluntad política, los POT no consideran el territorio más allá de las fronteras político administrativas del municipio. Al no concertarse con las localidades vecinas ni con la mayor parte de las autoridades que agencian intereses públicos no estrictamente locales, el peso de atender las realidades supramunicipales recae sobre las determinantes definidas por la ley ${ }^{43}$. En consecuencia, temas como la definición de los usos del suelo en zonas rurales y suburbanas colindantes con otros municipios, el manejo de ecosistemas estratégicos, redes o corredores ecológicos, equipamientos urbanos, infraestructuras o zonas de amenazas y riesgos, que por sus características y funcionalidades pueden ser optimizados si se gestionan de forma concertada y coordinada con una perspectiva supralocal, se han chocado con la dificultad práctica referida ${ }^{44}$.

En este orden, resulta favorable el arreglo competencial previsto por la LOOT, en virtud del cual, de conformidad con lo previsto por el artículo 1 del Acuerdo 10 de 2016 de la COT, los POD pueden:

a. Definir directrices y orientaciones con el fin de determinar los escenarios de uso y ocupación del espacio, especialmente en áreas de conurbación, en relación con: a) la conservación y protección del medio ambiente, la biodiversidad y los recursos naturales; b) la gestión del riesgo de desastres y la adaptación al cambio climático ${ }_{i}$ c) la conservación, preservación y uso de áreas e inmuebles calificados como patrimonio cultural de la nación o del departamento; d) las categorías de protección y desarrollo restringido del suelo rural, patrones de suburbanización, delimitaciones de unidades de planificación rural y el sistema de centros poblados; y e) el desarrollo rural sustentado en el ordenamiento productivo agropecuario, el ordenamiento social de la propiedad rural y la identificación de las áreas para la producción agropecuaria y el aprovechamiento sostenible de los recursos naturales.

b. Estatuir políticas de asentamientos poblacionales y centros urbanos, de manera que se facilite el desarrollo del territorio, en particular en relación con: a) la gestión del riesgo de desastres; b) la adaptación al cambio climático, por medio de la definición de orientaciones que permitan a los municipios

43 De aquí que algún sector de la doctrina haya manifestado que, por su papel decisivo dentro de la coordinación de las decisiones de las distintas autoridades implicadas en la planificación y gestión del territorio, las determinantes constituyen "la piedra angular" de la OT en Colombia, "pues disponen el mejor aprovechamiento de la geografía regional en beneficio, no de este o aquel distrito o municipio, sino de toda la comunidad circundante, cuando no de la Nación entera". Cfr. Luis Fernando Hernández Betancur, op. cit., p. 267.

44 Juana Mariño Drews, "Territorio...", op. cit., p. 456. Destaca la importancia de la aglomeración de infraestructuras, como vía efectiva para maximizar su impacto y obtener con ellas el mayor beneficio para el mayor número, Luis Fernando Hernández Betancur, op. cit., pp. 280-281. 
identificar y emprender acciones prioritarias en este frente ${ }_{i} \mathrm{c}$ ) la conservación, preservación y uso de áreas e inmuebles calificados como patrimonio cultural de la nación o del departamento; y d) los suelos urbano, rural y suburbano, lo mismo que los centros poblados rurales.

c. Dictar directrices y orientaciones para la localización de la infraestructura física-social, de forma que se aprovechen las ventajas competitivas regionales y se promueva la equidad en el desarrollo departamental en lo que tiene que ver con: a) infraestructura de la red vial nacional y regional, puertos, aeropuertos y vías de comunicación intermunicipales $;$ b) corredores viales suburbanos; c) los sistemas regionales de abastecimiento de agua, saneamiento básico y suministro de energía, así como el señalamiento de las áreas para el manejo, tratamiento y disposición final de residuos sólidos o líquidos; y d) equipamientos de escala regional o departamental, que se puedan ubicar en suelo rural de los municipios.

d. Impartir orientaciones y estrategias para articular los planes sectoriales con los planes municipales y de los grupos étnicos, e instrumentos que aseguren la articulación de los POD con las determinantes de los POT.

El cumplimiento oportuno y adecuado por parte de los departamentos de estas responsabilidades debería, por lo tanto, proporcionar a los municipios y distritos valiosas orientaciones para el mejor cumplimiento de su tarea de ordenación del territorio en sus jurisdicciones y hacer posible la corrección de los efectos negativos que ha comportado la insularización de la OT, adelantada hasta ahora con perspectiva esencialmente local. De aquí que sea razonable que el referido Acuerdo 10 de 2016 de la СОT haya contemplado en su artículo 1 que la expedición de un POD debería tenerse como una justificación válida para la modificación excepcional de los POT comprendidos dentro del territorio ordenado departamentalmente. Se trata, en últimas, de asegurar la concordancia y articulación de las distintas instancias a cargo de la materialización de los fines que la Constitución y la ley han señalado a la OT y a la ordenación urbanística del territorio.

\subsection{LOS BENEFICIOS DE UNA DECISIÓN UBICADA EN EL NIVEL INTERMEDIO}

La OT es una disciplina transversal ${ }^{45}$. Por sus características y función, articula e integra numerosos intereses y competencias ejercidas sobre el territorio. Su finalidad no es otra que asegurar la coordinación de las decisiones sectoriales (urbanismo, infraestructura, desarrollo rural, minería, prevención de desastres, medio ambiente, patrimonio histórico cultural, defensa y seguridad, etc.) que se adoptan en un espacio específico, en acuerdo con las comunidades y la 
amplia constelación de sujetos que ocupan el territorio ${ }^{46}$. En últimas, como lo expresó el Tribunal Constitucional Español en la sentencia TC-149/1991, la idea de OT "nació justamente de la necesidad de coordinar o armonizar, desde el punto de vista de su proyección territorial, los planes de actuación de distintas Administraciones". De ahí que su objeto sea, desde una perspectiva supralocal, "garantizar una adecuada estructura espacial para el desarrollo de las políticas económicas, sociales, ambientales y culturales ${ }^{\prime \prime 4}$. Esto incide y determina la manera como se ejerce esta competencia, que por su carácter horizontal y plurisectorial exige altas dosis de coordinación, cooperación y concertación interinstitucional ${ }^{48}$. Consecuencia de esta situación es habitual que la ordenación del territorio se ejerza en un orden administrativo distinto al municipal, superior a él, con mejores condiciones para desplegar la perspectiva más amplia que exige la materia y con mayor capacidad para liderar y encauzar los esfuerzos de coordinación interadministrativa -tanto en un sentido horizontal (intersectorial) como vertical (intergubernamental)- y de colaboración intersubjetiva que demanda esta competencia/política ${ }^{49}$.

El nivel intermedio en el que se encuentra el departamento parece entonces más adecuado que el local para cumplir con esta responsabilidad. No se trata únicamente de que por su posición institucional cuente con una visión más amplia y completa del territorio a ordenar; debe tenerse en cuenta, además, su mayor capacidad de interrelación con la pluralidad de actores que confluyen en el territorio (en especial con los públicos, del orden nacional, distrital o municipal, de una multitud de sectores), su condición natural de interlocutor en múltiples escenarios y su vocación de coordinación de numerosas tareas y responsabilidades. No en balde el artículo 298 de la Constitución les

46 Desarrolla las dimensiones e implicaciones políticas, sociales, simbólicas, identitarias y existenciales de la noción territorio, como idea claramente diferenciable de la de espacio, Alice Beuf, "El concepto de territorio: de las ambigüedades semánticas a las tensiones sociales y políticas", Ordenar los territorios. Perspectivas críticas desde América Latina, Bogotá: Universidad Nacional de Colombia - Universidad de Los Andes - Instituto Francés de Estudios Andinos, 2017, pp. 5 y ss.

47 Fernando López Ramón, op. cit., p. 69. En sentido similar sostiene Gómez Orea que la función de la ordenación del territorio consiste en "identificar, distribuir, organizar y regulas las actividades humanas en ese territorio de acuerdo con criterios y prioridades". Cfr. Domingo Gómez Orea, op. cit., p. 29.

48 AndREas Hildebrand SCHeID, "La política de ordenación del territorio de las comunidades autónomas: balance crítico y propuestas para la mejora de su eficacia", Revista de Derecho Urbanístico y Medio Ambiente, n. ${ }^{\circ}$ 230, 2006, p. 26. Disponible en línea http://hum117.uca. es/grupogial/paginas/docencia/otymadoc/hildembrand.

49 Así, en Alemania y Austria son los Länder; en Italia y Bélgica, las regiones; en España, las comunidades autónomas; y en Suiza, los cantones. Cfr. Andreas Hildebrand SCHEID, "Tres propuestas para una relación efectiva entre las escalas regional y local en materia de ordenación del territorio", en Territorialidad y buen gobierno para el desarrollo sostenible, Valencia: Universidad de Valencia, 2007, pp. 148-149. 
encomienda expresamente "funciones administrativas, de coordinación, de complementariedad de la acción municipal, de intermediación entre la Nación y los municipios y de prestación de los servicios que determinen la Constitución y las leyes". Y aun cuando es claro que las normas constitucionales perfilan al departamento como un prestador de servicios y un ejecutor de diversas tareas con criterio de subsidiariedad ${ }^{50}$, en últimas, como afirma, González Díaz, no hay duda que "la Constitución vislumbra a los departamentos como los entes articuladores entre los municipios, las regiones y la Nación para los diferentes sectores $^{\prime \prime 5}$.

Adicionalmente, se trata de instancias administrativas familiarizadas con la planificación regional ${ }^{52}$. De un lado, el artículo 53 del Acto Legislativo 1 de 1968 les responsabilizó de ejercer sobre los municipios "la tutela administrativa necesaria para planificar y coordinar el desarrollo regional y local y la prestación de servicios, en los términos que las leyes señalen". Asimismo, la Ley 38 de 1981 les atribuyó importantes responsabilidades en relación con la vinculación y armonización entre la planeación nacional y la planeación regional, distrital, metropolitana o municipal ${ }^{53}$. Estos antecedentes llevaron a que el artículo 298 de la Constitución señale la planificación y promoción del desarrollo económico y social de su territorio como parte de sus tareas constitucionalmente asignadas y a que el artículo 300 ídem faculte a las asambleas departamentales para expedir disposiciones relacionadas, entre otras, con la planeación y el desarrollo económico y social de su territorio, y para adoptar los planes y programas de desarrollo económico y social, así como de obras públicas.

La planeación departamental y la articulación de los distintos niveles de planeación es, puede decirse, uno de los cometidos esenciales del nivel intermedio desde una óptica constitucional. Las nulas posibilidades de entendimiento directo que existirían entre la nación y los 1122 municipios que hay en Colombia, lo mismo que las sentidas necesidades de apoyo financiero, asistencia técnica, intermediación, coordinación, seguimiento y evaluación

50 Subraya esta dimensión LiLIANA Estupiñán ACHurY, op. cit., pp. 206 y ss.

51 AndRÉs GonZález DíAZ, "Los departamentos y sus funciones ambientales dentro del SINA", en Sistema Nacional Ambiental, 15 años. Evaluación y perspectivas, Bogotá: Universidad Externado de Colombia, 2008, p. 61. Igualmente destaca la importancia de este rol articulador en materia ambiental Constanza Bejarano Ramos, "Funciones ambientales de los departamentos en Colombia", en Lecturas sobre derecho del medio ambiente, t. XVI, Bogotá: Universidad Externado de Colombia, 2016, pp. 190 y ss.

52 Para Estupiñán Achury, según su interesante estudio de esta instancia administrativa, la planeación constituye "Una función que caracteriza la razón de ser de los diversos niveles intermedios de gobierno en los distintos modelos territoriales descritos". Véase LiLIANA ESTUPIÑ̃́n ACHURY, op. cit., p. 209.

53 Artículos 20-23. Estas disposiciones fueron recogidas por el Decreto Ley 1222 de 1986 en sus artículos 17-20. 
de sus acciones, justifican que así sea. Consciente de esto de esto, como se aprecia, por ejemplo, en la Ley 715 de 2001, el legislador ha asignado al departamento importantes labores de planificación y coordinación en materia de educación, salud, servicios públicos, artes y práctica del deporte, recreación y aprovechamiento del tiempo libre en el territorio departamental.

Por estas razones, aun cuando el artículo 41 de la Ley 152 de 1994 le asignaba a los departamentos la responsabilidad de brindar orientaciones y apoyo técnico a los municipios para la elaboración de los POT, lo previsto por el artículo 29.2 de la LOOT constituye un avance notable, en tanto devuelve a esta instancia administrativa (después del fallo de la Corte Constitucional del año 2000) la capacidad de intervención con incidencia significativa en la OT.

Con ello no solo se copa el vacío existente en relación con la planeación territorial a escala regional -fundamentalmente a cargo, hasta ahora, de los planes de ordenación y manejo de cuenca (POMCA) expedidos por las autoridades ambientales-, sino que además se estatuye un instrumento capaz de impactar positivamente en la realidad de los territorios departamentales mediante la promoción de un desarrollo sostenible y territorialmente equilibrado, y de la competitividad, seguridad y cohesión económica y social del territorio, teniendo en cuenta sus particularidades y el marco general definido por la política nacional de OT. En últimas, como ha sido destacado por el Ministerio de Vivienda, una de las tareas de los POD

será ligar la política nacional de ordenamiento territorial al ordenamiento territorial del nivel municipal mediante el establecimiento de directrices y orientaciones que le permita a los departamentos por una parte establecer las mejores condiciones para su desarrollo y posición competitiva en el contexto nacional, y por otra señalar los principales aspectos sobre los cuales se orientarán los planes de ordenamiento territorial del nivel municipal, sin menoscabar la autonomía y competencia de los municipios en la definición de sus usos del suelo ${ }^{54}$.

De aquí que sea fundamental que los contenidos del POD se articulen con las políticas sectoriales nacionales $y$, en especial, con las políticas ambiental, de prevención de desastres, desarrollo rural, protección del patrimonio históricocultural, servicios públicos domiciliarios, infraestructura, minería y vivienda ${ }^{55}$.

54 Ministerio de Vivienda, Ciudad y Territorio, Bases conceptuales para la formulación del ordenamiento territorial departamental en el marco de la LOOT/ Ley 1454 de 2011 (Documento preliminar), Bogotá, 2012, p. 44. Disponible en línea https://colaboracion.dnp.gov.co/CDT/Desarrollo\%20 Territorial/Bases\%20conceptuales\%20para\%20la\%20formulaci\%C3\%B3n\%20del\%20 ordenamiento\%20territorial\%20departamental\%20-\%20MVCT.pdf.

55 Tal como ha sido sostenido por la COT, de conformidad con sus atribuciones legales, el rol fundamental del departamento en la От "es el de articulador de los asuntos supramunicipales del ordenamiento para darles un manejo integral y propiciar un desarrollo espacial equilibrado del conjunto del departamento y de zonas de su territorio o subregiones, buscando 
A la luz de esta situación, con miras a asegurar que estos instrumentos cumplen su papel articulador y de promoción de un desarrollo sostenible y equilibrado territorialmente, seguro, competitivo, equitativo y acorde con las necesidades de defensa y protección de los recursos naturales y del patrimonio histórico cultural, parece razonable que, como lo proponen la COT y la CEI, el contenido de los POD se ocupe de temas como ${ }^{56}$ :

a. Establecer directrices para promover la planificación y gestión del riesgo natural y antrópico, y apoyar las acciones que contribuyan a la gestión de riesgo en el territorio desde la escala departamental y regional.

b. Dar orientaciones para armonizar los usos y ocupación del suelo y las relaciones con el medio ambiente derivadas de los procesos productivos, orientando la localización de las actividades económicas en función del interés general y en armonía con el medio natural y construido.

c. Apoyar la declaratoria, el manejo efectivo y la consolidación de las áreas de conservación y protección ambiental y la identificación de la estructura ecológica del territorio y su armonización con el crecimiento urbano, el desarrollo productivo y el desarrollo rural de los municipios.

d. Identificar acciones organizadoras del territorio para orientar a conjuntos de municipios con intereses comunes, procurando un equilibrio entre el crecimiento urbano, la expansión y la conservación de las áreas rurales y de las áreas de especial importancia ecosistémica que sean comunes entre municipios y departamentos.

e. Definir modelos de organización del sistema de ciudades y estrategias para la formación de redes buscando complementariedad y equilibrio territorial.

f. El establecimiento de las condiciones mínimas para el desarrollo de proyectos de interés público y social (que pueden ser de índole turística, minera, etc.) según el Decreto 2201, buscando su armonización con el ordenamiento ambiental del territorio y la gestión prospectiva del riesgo.

g. Establecer proyectos estratégicos en servicios públicos, vías, transporte y equipamientos en coordinación con los municipios para promover alianzas

además que dicho ordenamiento territorial, a raíz de su naturaleza multidimensional, se constituya en articulador de la planificación sectorial, guiando además la organización del sistema de asentamientos poblacionales". Cfr. Secretaria Técnica de la COT, Comité Especial Interinstitucional, Lineamientos para el proceso de ordenamiento territorial departamental. Contenidos básicos, Bogotá: DNP, p. 15. Disponible en línea https://www.usbcali.edu.co/sites/ default/files/lineamientosdelacot.pdf.

56 Ibíd., pp. 19-20. En sentido similar, véanse los contenidos propuestos por el Ministerio de Vivienda, Ciudad y Territorio, op. cit., pp. 45-46. Un enfoque distinto de los contenidos se aprecia en Departamento Administrativo Nacional de Planeación, Elementos para la formulación de la política nacional de ordenamiento territorial y alcances de las directrices departamentales, Bogotá, 2013, p. 28. Disponible en línea https://colaboracion.dnp.gov.co/CDT/Desarrollo\%20Territorial/Documento\%20PNOT-LOOT.\%20DDTS\%20-\%20SODT.\%2011\%20junio\%20013. pdf. 
regionales y subregionales, y optimizar los beneficios de la planificación regional, buscando la reducción de los desequilibrios subregionales al interior del departamento.

De esta forma, por sus contenidos, perspectiva supramunicipal y vocación integradora, los POD deberían estar llamados a jugar un papel fundamental dentro del sistema de ordenación del territorio en Colombia. Su expedición debería facilitar e impulsar la adopción de decisiones más coordinadas, eficientes y sostenibles por parte de los municipios en asuntos cruciales para este campo, como la protección y gestión de ecosistemas estratégicos y recursos naturales, la clasificación de los suelos y la regulación de sus usos, el manejo integral de las amenazas y riesgos para la seguridad de los asentamientos, la promoción y defensa de las áreas de producción agropecuaria, en resguardo de la seguridad alimentaria de una región y en pro de un crecimiento urbano más racional, el desarrollo de infraestructuras de escala regional para la prestación de servicios públicos domiciliarios, la estructuración de sistemas de transporte, infraestructura vial y equipamientos que atiendan las necesidades a nivel supramunicipal, y la orientación de la localización de soluciones de vivienda y actividades económicas en función del interés general expresado en viabilizar un desarrollo económico sostenible, centrado en la competitividad, el equilibrio regional, el aprovechamiento racional de los recursos naturales y el mejoramiento de la calidad de vida de la población.

\section{LOS RIESGOS DE LOS POD PARA EL MODELO DE ORDENACIÓN TERRITORIAL EN COLOMBIA}

Ahora bien, con ser cierto que los POD están llamados a cumplir un papel fundamental en relación con facilitar la ordenación, planificación y gestión del territorio a una escala intermedia, asumiendo además un papel de bisagra o de articuladores entre la política de От de la nación y sus estrategias de planificación sectorial y los municipios, no cabe duda de que tal como están siendo impulsados, esto es, bajo el actual marco normativo, dada su absoluta precariedad, su expedición comporta serios riesgos para principios esenciales del esquema constitucional de ordenación del territorio. En efecto, debido a la ausencia de un régimen legal que discipline, enmarque y oriente de manera adecuada la competencia que la LOOT atribuyó a los departamentos, principios vertebrales de este sector del derecho como la legalidad de las actuaciones de la Administración (2.1), la autonomía local y la participación ciudadana (2.2), se encuentran expuestos a serias amenazas. 
2.1. LA AUSENCIA DE UNA REGULACIÓN LEGAL QUE ENMARQUE

Y ORIENTE EL EJERCICIO DE LA COMPETENCIA POR PARTE

DE LOS DEPARTAMENTOS Y LA AMENAZA AL PRINCIPIO DE LEGALIDAD

En un Estado democrático de derecho como el instaurado en Colombia por el artículo 1 de la Constitución, en ocasiones el ejercicio de ciertas competencias por parte de las autoridades demanda más que la sola atribución legal del poder de tomar una decisión en una materia específica. Tener competencia es, sin duda, un presupuesto inexcusable de cualquier actuación pública ${ }^{57}$; pero, normalmente, se necesita algo más: un régimen legal que defina los aspectos fundamentales de la función a desarrollar. Ello resulta crucial para las actuaciones administrativas. De ordinario, la Administración precisa contar con un marco legal completo, eventualmente expedido ex novo, para posibilitar el ejercicio de sus competencias sin atentar contra principios, derechos o garantías institucionales del modelo constitucional vigente $(v \cdot g r$ la separación de poderes, el principio de legalidad, derechos y garantías civiles fundamentales, la garantía de la autonomía territorial, etc.). Las particularidades del régimen legal dependerán de múltiples factores, como el tipo de competencia (discrecional o reglada), su objeto (la ejecución de la ley, la regulación de un ámbito de la realidad, la planificación de un sector, la prestación de un servicio, etc.), el ámbito normativo en el que se lleva a cabo (con o sin reserva de ley impuesta por la Constitución a efectos de su regulación) y el sector en el que se inscribe (en aras de determinar si existen normas generales aplicables a esa competencia o si precisa de una reglamentación especial).

Así, por ejemplo, no es lo mismo tipificar una nueva infracción de tránsito (v. gr. conducir bajo el efecto del alcohol u otra sustancia que altere los sentidos de la persona) y reconocer a la autoridad respectiva la facultad de sancionar a quienes incurren en dicho comportamiento ${ }^{58}$ (algo para lo que se puede aplicar todo el acervo normativo sustancial y procedimental previamente establecido por el legislador en dicho campo), que instaurar una autoridad que regule las telecomunicaciones. Debido a la reserva legal estatuida por el artículo 365 de la Constitución en materia de servicios públicos, la enorme constelación de intereses afectados, la pluralidad de sujetos involucrados y la reconocida complejidad técnica de la actividad regulatoria (que, en su versión más estricta,

57 Conforme ha recalcado la jurisprudencia constitucional, "mal puede en un Estado de de recho hacerse valer atribuciones, funciones o competencias que no estén expresamente y de manera previa señaladas en la Constitución o la ley. Cualquier ejercicio -por parte de un órgano del Estado o de un servidor público de este- de atribuciones, funciones o competencias que no estén expresa y previamente indicadas en la Constitución o la ley, es un acto arbitrario y despótico y por ende abiertamente inconstitucional". Véase Corte Constitucional, sentencia C-319 de 2007.

Algo que hizo la Ley 1548 de 2012 en un solo artículo. 
comprende una pluralidad de formas de intervención del Estado en un sector específico de la economía con el fin corregir las fallas del mercado y asegurar el logro objetivos de interés público ${ }^{59}$ ), el legislador tiene la responsabilidad de definir un marco general sustantivo, procedimental y organizativo para su ejercicio ${ }^{60}$. Ello implica la fijación de principios, criterios, fines e instrumentos, así como la configuración de procedimientos, estructuras organizativas y límites específicos que orienten y enmarquen las acciones de la autoridad instituida. En ausencia de estas determinaciones, el legislativo deberá remitir a algún régimen legal aplicable (otro en vigor, como el que rige a las comisiones reguladoras en materia de servicios públicos domiciliarios, por ejemplo), puesto que la sola designación de un órgano como detentador de dicha competencia, dadas las particularidades de su régimen jurídico constitucional, no sería suficiente para su ejercicio. La complejidad de la responsabilidad encomendada, sumada a la reserva de ley que preside el ámbito de los servicios públicos, la pluralidad de intereses (públicos, privados y colectivos) presentes en este campo y a la necesidad de enmarcar y orientar sustancial y procedimentalmente la discrecionalidad inherente al ejercicio de la regulación, exigen que así sea. Adicionalmente entra en juego el principio de legalidad, entendido aquí en su versión de doble mandato constitucional, derivado del principio de Estado democrático de derecho, de dirigir el legislador la acción de la Administración, por un lado, y de actuar esta con fundamento y apego a lo establecido en la ley ${ }^{61}$, por el otro; el cual se acentúa en ámbitos constitucionalmente reservados a la ley. En consecuencia, como ha señalado la jurisprudencia constitucional, "tratándose de una materia reservada a la ley, corresponde al legislador determinar de manera precisa el ámbito para el despliegue de la discrecionalidad administrativa, sin que sea posible que por la amplitud del mismo, se deje librado a la Administración aquello para lo cual, precisamente, se estableció la reserva"62. No hacerlo conlleva desconocer las implicaciones de la reserva de ley impuesta por la Constitución frente a una materia específica.

59 Al respecto, véase, por ejemplo, DAVID GUINARD HERNÁNDEZ, "La regulación económica como instrumento de dirección estatal de la economía", Revista digital de Derecho Administrativo, n. ${ }^{\circ} 18,2017$, pp. 178 y ss.

60 Así lo ha reconocido la Corte Constitucional, por ejemplo, en sentencias como la C-150 de 2003 o la C-263 de 2013.

61 Véase José María Rodríguez de Santiago, Metodología del..., op. cit., p. 20.

62 Corte Constitucional, sentencia C-9974 de 2002. Este pronunciamiento, que es proferido con ocasión del control a una previsión de Ley 715 de 2001 que habilitaba en términos muy amplios al Ministerio de Salud para intervenir sobre las instituciones prestadoras de salud, resulta por completo extrapolable a otros ámbitos que comparten el estar presididos por una reserva de ley y envolver competencias administrativas discrecionales. Es lo que ocurre, justamente, en materias como las telecomunicaciones y la От. Por ende, no cabe duda que dicha postura jurisprudencial es extensible al asunto que nos ocupa. 
En este orden, más que por capricho o prurito doctrinal, la exigencia de una ley provista de una densidad adecuada y unos contenidos que abarquen los principales aspectos organizativos, procedimentales y sustanciales de la decisión de OT que se faculta adoptar a los departamentos, obedece a un requerimiento constitucional ineludible: el principio de legalidad. Proclamado por el artículo 6 de la Constitución, impone como una de sus principales consecuencias que "Los particulares sólo son responsables ante las autoridades por infringir la Constitución y las leyes. Los servidores públicos lo son por la misma causa y por omisión o extralimitación en el ejercicio de sus funciones". Obliga, por tanto, a que le ley estructure las condiciones fundamentales de ejercicio de las competencias que ella o la Constitución atribuyen, de suerte que la Administración cuente con elementos suficientes para conocer y ejercer su responsabilidad sin incurrir en excesos (extralimitaciones) ni defectos (omisiones).

Este principio representa una base fundamental de cualquier actuación de una autoridad administrativa en el marco de un Estado democrático de derecho. En especial cuando, como ocurre en este caso, dicha actuación tiene lugar en un ámbito presidido por una reserva de ley; derivada de los artículos 334 (que reserva a la ley la intervención del Estado en los usos del suelo y el aprovechamiento de los recursos naturales) y 287 (que garantiza a las entidades territoriales autonomía para la gestión de sus intereses y dispone que esta solo podrá ser restringida por la Constitución o la ley) constitucionales. El mandato constitucional general de obrar de la Administración conforme al marco legal definido se torna, así, más astringente.

Debido a que la reserva de ley comporta una delimitación de ámbitos materiales cuya regulación debe ser emprendida exclusivamente por normas con rango legal, su definición frente a un asunto concreto, a la par que impone al legislador "la obligación de ejercer su competencia normativa bajo unas determinadas condiciones, $[\ldots]$ veda al reglamento su intromisión sin una cobertura legal adecuada"63. En últimas, como explica Parejo Alfonso, la reserva de ley de una materia conlleva que "la regulación de dichos ámbitos debe producirse, en primera instancia, mediante leyes en sentido formal o, en todo caso y con alguna limitación, por normas que, aún emanadas del Gobierno correspondiente, tienen rango y fuerza de ley"64. Según ha sostenido la jurisprudencia constitucional, la reserva de ley "no significa que el legislador debe regular íntegramente la materia, incluso en sus aspectos más específicos. En contrario

63 Héctor Santaella Quintero, "Del principio de legalidad al principio de juridicidad: implicaciones para la potestad normativa de la administración de una transición constitucionalmente impuesta", La Constitucionalización del Derecho Administrativo. XV Jornadas Internacionales de Derecho Administrativo, Bogotá: Universidad Externado de Colombia, 2014, p. 109.

64 Luciano Parejo Alfonso, Lecciones de derecho administrativo, 3. a edición, Bogotá: Tirant lo Blanch - Universidad Externado de Colombia, 2011, p. 96. 
[sic], la competencia exclusiva del legislador está relacionada con la fijación de los aspectos esenciales y definitorios del asunto objeto de reserva legal, la cual no puede ser de ningún modo diferida al reglamento" ${ }^{165}$. Por ende, no supone que la ley tenga el mandato constitucional de agotar con sus previsiones la totalidad de la materia susceptible de regulación, ni tampoco que el reglamento quede por completo privado de cualquier posibilidad de incidencia en la materia regulada. Al legislador corresponderá, por mandato constitucional, definir las bases fundamentales (sustantivas, procedimentales y organizativas) del régimen jurídico respectivo ${ }^{66}$. El reglamento, entonces, tendrá el ámbito normativo que por disposición constitucional le corresponda (v.gr. la reserva de acuerdo municipal del concejo en materia de usos de suelo) o que el legislador le remita en atención a consideraciones políticas, técnicas o materiales de otra índole, siempre que, por supuesto, se respete el mandato de definición legal de los aspectos centrales o esenciales del ámbito regulado.

Pues bien, a la vista de las implicaciones concretas que deberían tener los POD sobre la autonomía municipal para ordenar su territorio y su notable incidencia sobre la regulación de los usos de suelo y el aprovechamiento de los recursos naturales, no cabe duda que las reservas de ley estatuidas por los artículos 287 y 334 de la Constitución se activan en este caso y demandan del legislador una particular implicación y diligencia en la regulación de este asunto. Ello impone la exigencia de un marco legal sustantivo, organizativo y procedimental apto para disciplinar y encausar de manera efectiva el ejercicio cabal de esta competencia. No obstante, hasta el momento no ha sido así. A la fecha, estos instrumentos se vienen desarrollando con base en la nítida competencia otorgada por el artículo 29.2 de la LOOT, pero con el endeble soporte que ofrecen las nociones desarrolladas por documentos orientado-

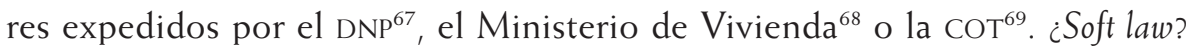
Puede ser. Sin embargo, la ausencia absoluta de una referencia legal (tanto a

65 Corte Constitucional, sentencia C-228 de 2010. En sentido similar, véase la sentencia C-690 de 2003.

66 Se trata, como ha sido indicado por el Consejo de Estado, de someter estas decisiones al procedimiento parlamentario y al tamiz del debate público, plural, representativo, participativo y dilatado en el tiempo que es inherente a esta clase de decisiones, con el fin no solo de "imprimir mínimos de legitimidad y de racionalidad a las normas que rigen sectores cruciales del ordenamiento jurídico; se apunta también a asegurar la materialización de los principios democrático, pluralista y de separación de poderes". Cfr. Consejo de Estado, Sala de lo Contencioso Administrativo, Sección Primera, sentencia del 13 de octubre de 2016, Rad. 11001-03-24-000-2013-00257-00.

67 Véase, por ejemplo, el documento Departamento Administrativo Nacional De Planeación, Elementos para la..., op. cit.

68 Véase, Ministerio de Vivienda, Ciudad y Territorio, op. cit

69 Cfr. Secretaria Técnica de la COT, op. cit. También expidió la COT el Acuerdo 10 de 2016 "Por el cual se expiden y recomiendan lineamientos y criterios para la reglamentación de los Planes de Ordenamiento Departamental (POD)". 
nivel de la LOOT, como de la LDU o de cualquier otra norma con rango de ley) en relación con el procedimiento de expedición o revisión de los POD, los sujetos que intervienen en estas decisiones, los fines, criterios o contenidos que deben considerar los departamentos al adoptarlos, así como respecto de cuáles deben ser las claves fundamentales de su relacionamiento con los POT o la política nacional de OT (en términos de su jerarquía, por ejemplo), resulta preocupante y problemática.

Sin duda, el intento más acabado por establecer algún parámetro normativo que oriente sustancial y procedimentalmente esta competencia departamental es el Acuerdo 10 de 2016 de la сот. En él se fijan algunas definiciones relevantes, se incorporan principios para su ejercicio, se caracterizan los rasgos fundamentales de la OT departamental, se enuncian contenidos del POD, se indica el procedimiento que deben seguir los departamentos para su expedición, se señala que la expedición de un POD es causal de revisión excepcional de los POT afectados y, entre otras, se menciona cuál debería ser la vigencia de los POD en el tiempo. La cuestión, no obstante, radica en que la COT es un organismo de carácter asesor, cuya función, según lo dispone el artículo 4 de la LOOT, es "evaluar, revisar y sugerir al Gobierno nacional y a las Comisiones Especiales de Seguimiento al Proceso de Descentralización y Ordenamiento Territorial del Senado de la República y de la Cámara de Representantes, la adopción de políticas, desarrollos legislativos y criterios para la mejor organización del Estado en el territorio". Por ende, carece por completo de competencias regulatorias; razón por la cual no cuenta con la facultad de definir el régimen de los POD. Sus competencias no pueden ir más allá de lo dispuesto por la ley. No debe olvidarse, además, que por tratarse de un asunto con reserva legal, solo una norma con rango legal puede sentar sus aspectos fundamentales. En consecuencia, al tener la СOT facultades puramente asesoras, sus determinaciones (no importa el nomen iuris que se les dé) no pueden valer más allá de lo que son: simples recomendaciones al Gobierno nacional y al legislativo en materia de desarrollos normativos posibles. Los cuales, para adquirir rango de derecho capaz de fundamentar actuaciones como la expedición de los POD, tendrán que ser previamente discutidos y adoptados por los respectivos órganos competentes (en este caso, en primer lugar, por el legislador).

Es preciso, por lo tanto, contar con un régimen legal que se ocupe de regular la От departamental tanto en lo sustancial, como en lo procedimental y organizativo. Sea en una ley especial o en una norma que modifique o adicione la LDU, el legislador debe asumir su responsabilidad frente a esta materia. De lo contrario, su ausencia condenará a esta competencia a permanecer en un limbo sobre sus verdaderas condiciones de ejercicio. Si bien, operativamente, se podría pensar que los fines que el artículo 3 de la LDU define para la OT municipal son predicables por igual de los POD, y que lo mismo sucede con los principios del artículo 2 ídem, quedan vacíos notables. ¿Cuál es el procedimiento de expedición y revisión del POD? ¿Quiénes deben intervenir en estas 
instancias de discusión y con qué facultades? ¿Cuáles son sus determinantes? ¿Cuál es su vigencia? ¿Cuáles son sus contenidos y componentes fundamentales? ¿Qué valor jurídico y rango jerárquico se les reconoce frente a los POT?

Parece imperioso que el legislador dé respuesta a estos interrogantes. Se trata de reglas esenciales para la aplicación de estos instrumentos y el ejercicio cabal de esta competencia, que difícilmente pueden derivarse de la extensión del régimen previsto por la LDU para los POT y que, en virtud de la reserva de ley que cubre esta materia, no podrían ser definidos por un reglamento del presidente. Podría discutirse, con base en el argumento de la garantía de la autonomía territorial (artículo 287 de la Constitución), si resultaría legítimo que a partir de la competencia constitucional expresa que tienen las Asambleas Departamentales para dictar normas sobre la planeación del desarrollo de su territorio (artículo 300.2 de la Constitución), a falta de regulación legal sobre la materia, aquellas pueden ejercer sus atribuciones constitucionales y colmar dicho vacío ${ }^{70}$. Ello supondría que cada Asamblea Departamental pasaría a definir por medio de ordenanza el régimen de ejercicio de la competencia que la LOOT le atribuyó a los departamentos, al menos hasta que el legislador ejerza su responsabilidad y defina el régimen legal de esta materia. Con todo, aunque personalmente encuentro esta postura razonable y ajustada al régimen constitucional de la autonomía territorial que rige en Colombia y a su sistema de fuentes, no la veo compatible con el todavía prevalente enfoque centralista de nuestra jurisprudencia ${ }^{71}$. Además, aun cuando permitiría resolver el problema de la ausencia de un régimen jurídico apto para viabilizar el ejercicio de la competencia que el artículo 29.2 de la LOOT reconoce a los departamentos, quedaría sin atender la cuestión (no menor) de cómo interactúan los POD y los POT, dado que solo por ley es legítimo restringir la autonomía local en lo que concierne al ejercicio de su competencia constitucional en materia de regulación de los usos de suelo (artículo 313.7 de la Constitución) ${ }^{72}$. Cuáles deben ser los determinantes de los POD o con qué alcance se estructura la participación de

70 Una postura similar, de relativización de la reserva de ley y favorecimiento de la garantía de la autonomía territorial en presencia de intereses territoriales, que se concreta en un reconocimiento de un esquema de vinculación negativa (y no positiva) de los reglamentos municipales a la ley, se ha discutido en España. Véase Jorge FernándeZ-Miranda FERNÁNDEZ-Miranda, "El principio de legalidad, la vinculación negativa y el ejercicio de la potestad reglamentaria local", RAP, n. ${ }^{\circ} 196,2015$, pp. 241 y ss. También Alfredo GaLÁN GaLÁN, "La consolidación del principio de vinculación negativa en el ámbito local", Revista Cemci, n. ${ }^{\circ} 8,2010$, pp. 2 y ss. Disponible en línea https://revista.cemci.org/numero-8/pdf/ articulo2.pdf.

71 Aunque debe admitirse que, desde la sentencia C-123 de 2014, la jurisprudencia constitucional ha comenzado un interesante giro más garantista y abierto hacia la autonomía territorial. Ello se aprecia, por ejemplo, en las sentencias C-035 de 2016, C-273 de 2016 y C-346 de 2017.

72 Más aún, según la muy cuestionable postura asumida por la jurisprudencia constitucional en la sentencia C-273 de 2016, esta clase de inmisiones del legislador en ámbitos 
entes como las autoridades ambientales (CAR) en el trámite de expedición de estos instrumentos son también interrogantes que, por sus implicaciones materiales, solo la ley podría resolver.

En consecuencia, sea cual sea la postura que se asuma (de defensa estricta de la reserva de ley que preside esta materia, o de relativización de esta a favor de una ampliación de la autonomía territorial, que dé vía libre a la regulación de este asunto por medio de ordenanza departamental expedida en ejercicio de la competencia constitucional para regular los asuntos concernientes a la planificación del desarrollo de su territorio), una ley que defina los aspectos fundamentales de esta materia parece ineludible.

\subsection{LA AMENAZA PARA LA AUTONOMÍA LOCAL Y LA PARTICIPACIÓN CIUDADANA}

La ausencia de un marco legal adecuado para el ejercicio de la competencia de adopción de POD por parte de los departamentos no solo comporta un serio inconveniente desde el punto de vista de la legalidad de la actuación que se desarrolla. Por la falta de un procedimiento de formulación y adopción legalmente estatuido hay también una seria amenaza para la autonomía local y la participación ciudadana. Además, la forma amplia y vaga como está reconocida dicha atribución departamental, sumada a la ausencia de una regla que especifique la forma como los POD interactúan con los POT, entrañan un riesgo adicional para la autonomía territorial. $\mathrm{Si}$, tal como ha sido descrito por la jurisprudencia constitucional más reciente, la OT resulta esencial para la vida de las comunidades locales en tanto sus determinaciones, y en especial las concernientes a los usos del suelo, "afectan aspectos axiales a la vida en comunidad y llegan a determinar el modelo de desarrollo y, por consiguiente, las condiciones de vida en aspectos como el económico, el social, el cultural, el ambiental, el urbanístico, entre otros ${ }^{1173}$, no cabe duda que la autonomía local y la participación ciudadana constituyen aspectos neurálgicos de esta materia, cuyo menoscabo o amenaza debe ser objeto de reflexión.

En cuanto al riesgo que representa para la autonomía local la expedición de los POD debe decirse, en primer lugar, que su existencia no es per se incompatible con la garantía estatuida por el artículo 287 de la Constitución, ni se puede ver como una barrera para el ejercicio de la competencia otorgada a los entes locales por el artículo 313.7 ídem. En últimas, como ha enfatizado la jurisprudencia constitucional,

competenciales constitucionalmente atribuidos a los entes locales solo resultan legítimas si se efectúan por el legislador por medio de la LOOT.

73 Corte Constitucional, sentencia T-445 de 2016. En sentido similar, véase la sentencia C-123 de 2014. 
en materia de desarrollo urbano, ordenamiento territorial, obras de infraestructura y política de vivienda, la Constitución asigna competencias concurrentes a órganos del orden nacional y territorial, sin delimitar de manera rígida su ámbito material, ni atribuir funciones específicas. Así, para desarrollar la Constitución y articular la concurrencia de competencias, el legislador goza de una amplia potestad configurativa, la cual, sin embargo, debe sujetarse a diversos parámetros constitucionales ${ }^{74}$.

Por ende, aun a falta de base constitucional expresa, es legítimo que en desarrollo de su libertad de configuración de las materias cuya regulación le ha sido constitucionalmente encomendada, el legislador introduzca un instrumentos como los POD y les asigne un papel primordial en la cristalización de los objetivos globales de la OT. Ahora bien, como lo resalta la Corte Constitucional, es preciso que dicha regulación se dé con total apego a los parámetros constitucionales que enmarcan esta clase de determinaciones del legislador, a quien está vedado anular o restringir de manera desproporcionada la autonomía territorial y las atribuciones fundamentales de los entes territoriales ${ }^{75}$.

En este orden de ideas, debe partirse del hecho que hasta el momento en que se expidan los POD, en el marco de la amplia discrecionalidad que la LDu les ha conferido, corresponde a los municipios definir autónomamente qué parte de su suelo se clasifica como urbano, de extensión urbana o rural; establecer la zonificación y definición de los usos, la intensidad de los usos y tratamientos que se deben asignar a las diferentes partes de la ciudad, localizar y determinar las características de la infraestructura y los espacios públicos; definir espacios libres para parques y áreas verdes públicas; reservar los terrenos para la expansión de la infraestructura urbana; situar los terrenos para la construcción de vivienda de interés social y, entre muchas otras tareas propias de esta competencia, identificar las zonas no urbanizables por presentar riesgos para los asentamientos humanos, lo mismo que las áreas críticas de recuperación y control para la prevención de desastres, los bienes y conjuntos merecedores de salvaguarda y los ecosistemas de importancia ambiental para el municipio para su protección y manejo adecuados. Debido al solapamiento espacial que tiene lugar entre POT y POD, y a la comunión de fines que existe entre la ordenación urbanística del territorio a cargo de los municipios y la OT departamental, en virtud del mandato constitucional de coordinación (artículo 288) ${ }^{76}$, su interrelación debería, en principio, resultar forzosa. Por este motivo, partiendo de la perspectiva supramunicipal que caracteriza a las decisiones de OT a cargo de

74 Corte Constitucional, sentencia C-149 de 2010.

75 En este sentido, véase, por ejemplo, la sentencia C-123 de 2014.

76 Sobre el sentido de este principio, puede consultarse PAULA RoBledo SiLVA, "Los principios de coordinación, concurrencia y subsidiariedad: una posible solución a la problemática del reparto de competencias en materia minera", Minería y desarrollo. Historia y gobierno del territorio minero, t. 5, Bogotá: Universidad Externado de Colombia, 2016, pp. 257 y ss. 
los departamentos, sus directrices, orientaciones y políticas, deberían aportar insumos cruciales para la formulación de los $\mathrm{POT}^{77}$.

Ahora bien, tanto la ausencia de un procedimiento legalmente estatuido para la expedición de los POD, como la amplitud e indeterminación de los enunciados normativos del artículo 29.2 de la LOOT que concretan la competencia de los departamentos para expedir estos instrumentos de OT, levantan temores fundados sobre su eventual incidencia negativa respecto de la autonomía local. Lo primero, debido a que a falta de una estructura procedimental preestablecida, que permita conocer con anticipación no solo cuál será el iter o secuencia a seguir para la expedición de estos instrumentos, sino también (y en especial) quiénes y con qué alcance y prerrogativas intervendrán en él, el papel que en dicho trámite incumbe a los municipios resulta del todo incierto. Siendo el procedimiento la instancia natural para la identificación, ponderación y articulación de los intereses locales eventualmente afectados por las determinaciones del POD, su implicación activa en dicho trámite resulta crucial. De aquí que debe estar contemplada de algún modo por la legislación que reglamente este asunto. En últimas, si, como ha señalado la jurisprudencia, la atribución constitucional de una competencia a los municipios como la del artículo 313.7 no puede equipararse a la instauración de un monopolio de decisión o gestión en cabeza del ente local, pero evidencia un interés territorial irreductible, en cuya defensa la garantía institucional de la autonomía demanda el respeto del derecho del municipio a participar en su gestión y decisión ${ }^{78}$, parece razonable exigir alguna forma de intervención de los entes locales en la discusión y tramitación de los POD.

De otra parte, y en cuanto al segundo factor de riesgo apuntado, se tiene igualmente que la notable indeterminación de las atribuciones competenciales del departamento, según lo dispuesto por el artículo 29.2 de la LOOT, es otra fuente de amenaza para la autonomía local en el ejercicio de su función constitucional de reglamentar los usos del suelo. Ciertamente, aun cuando no cabe duda que el arreglo competencial sancionado por la LOOT no puede entenderse como una atribución en virtud de la cual los entes departamentales puedan desplazar a los municipios en el ejercicio de su competencia constitucional de reglamentar los usos de suelo, no es menos cierto que los enunciados

77 Instituto de Estudios Urbanos, "Planes de Ordenamiento Territorial Departamental frente a los Municipios", Debates de Gobierno Urbano, n. ${ }^{\circ} 8,2016$, pp. 6 y ss.

78 Cfr. las sentencias C-535 de 1996 y C-123 de 2014 de la Corte Constitucional, en las que se ha defendido la tesis según la cual, más que en una garantía de decisión final o gestión plena, el núcleo esencial de la autonomía territorial se concreta en el derecho del municipio a participar a través de órganos propios en la administración y decisión de los asuntos de interés local. Un análisis de esta postura jurisprudencial y de su aplicabilidad en materia de ot se encuentra en Héctor Santaella Quintero, "El autogobierno del...", op. cit., pp. 771 y ss. 
normativos que estatuyen las competencias resultan bastante ambiguos o indeterminados, lo cual dificulta acotar el ámbito material concreto sobre el cual recae dicha competencia. Es decir, si bien una interpretación sistemática de la Constitución y la ley ofrece un criterio negativo cierto, válido para deslindar la competencia departamental de la municipal y fijar un límite claro al poder que se les reconoce a las autoridades departamentales en esta materia (a saber: la competencia del artículo 29.2 de la LOOT no puede en ningún caso significar la invasión ni la usurpación por parte de los departamentos de la responsabilidad municipal de reglamentar los usos del suelo), no resulta sencilla su determinación en positivo (esto es, la fijación concreta de las decisiones que pueden o deben adoptar los departamentos en este campo).

Así, si bien se podría decir que dicha competencia no puede ir más allá de lo legalmente establecido en el artículo 29 de la LOOT y, por lo mismo, los entes intermedios no están facultados más que para adoptar directrices y orientaciones para el ordenamiento de la totalidad o porciones específicas de su territorio, especialmente en áreas de conurbación, con el fin de determinar los escenarios de uso y ocupación del espacio, de acuerdo con el potencial óptimo del ambiente y en función de los objetivos de desarrollo, potencialidades y limitantes biofísicos, económicos y culturales $^{79}$, o para la localización de la infraestructura física-social, de manera que se aprovechen las ventajas competitivas regionales y se promueva la equidad en el desarrollo municipal ${ }^{80}$, o para dictar las políticas de asentamientos poblacionales y centros urbanos, de tal manera que facilite el desarrollo de su territorio ${ }^{81}$, no es menos cierto que en la práctica ello sigue siendo incierto. La indeterminación de expresiones como fijar "directrices", "orientaciones" o "políticas" está en la base de dicha incertidumbre. De una parte, se trata de fórmulas generales que no fueron objeto de una definición legal. De otra, su definición por medio de su significado usual no aporta mayores certidumbres ${ }^{82}$; como tampoco lo hace su definición por el Acuerdo 10 de la $\mathrm{COT}^{83}$. La pregunta de hasta dónde pueden llegar las

79 Artículo 29.2, literal a, LOOT.

80 Artículo 29.2, literal c, ídem.

81 Artículo 29.2, literal b, ídem.

82 Para la RAE, una directriz es una "idea que dirige" o la "instrucción o norma que ha de seguirse en la ejecución de algo"; al paso que una orientación es la "Posición o dirección de algo respecto a un punto cardinal". Una política, finalmente, hace referencia al "Arte o traza con que se conduce un asunto o se emplean los medios para alcanzar un fin determinado", o las "Orientaciones o directrices que rigen la actuación de una persona o entidad en un asunto o campo determinado".

83 El artículo 1 del Acuerdo 10 de 2016, en su primera parte, entre numerosas definiciones que ofrece, define lo que se debe entender por directriz, orientación y política de От. No obstante, lo hace en términos tan ambiguos, que aporta poco para el propósito de acotar, en positivo y a ciencia cierta, el ámbito material cubierto por la competencia de От departamental. Así, define las directrices como "reglas de obligatorio cumplimiento, 
reglas o instrucciones que se definan en virtud de esta facultad queda sin una respuesta distinta a la que se obtiene en aplicación del criterio negativo: no podrán, en ningún caso, reglamentar los usos del suelo, por tratarse de un asunto reservado por la Constitución a los concejos municipales (artículo 313.7 de la Constitución). El riesgo para la autonomía local es, pues, manifiesto.

De aquí que una aproximación más completa a este asunto demande tomar en consideración criterios materiales como el principio constitucional de subsidiariedad y la función esencialmente articuladora y de coordinación que está a cargo de la ОT departamental. El principio de subsidiariedad resulta relevante porque si, como ha sido establecido por la jurisprudencia constitucional, "reconoce el papel primordial del municipio como entidad eje de todo el ordenamiento ${ }^{184}$ y se traduce en que las instancias administrativas superiores "solo pueden intervenir en los asuntos propios de las instancias inferiores cuando éstas se muestren incapaces o sean insuficientes para hacerlo" ${ }^{115}$, permite entender que la intervención departamental en este ámbito no se sujeta únicamente al criterio negativo de la no usurpación de la decisión final de reglamentar los usos del suelo ${ }_{i}$ hay también, entonces, un canon constitucional que enmarca y contiene dicha determinación y le impide suplantar al municipio en decisiones para las cuales este se encuentra técnica y materialmente capacitado. Las facultades del departamento deben tener, entonces, un sentido distinto a la clasificación del suelo, la determinación concreta de usos, intensidades de usos, tratamientos y normas urbanas, a cargo de los entes locales. Ello lo confirma el criterio funcional de tomar en consideración el papel esencialmente articulador y coordinador que, en línea con el rol constitucional de los

establecidas para asegurar el desarrollo del modelo de ordenamiento y facilitar la articulación sectorial y armonización de las disposiciones departamentales con las políticas y planes del nivel nacional, las áreas metropolitanas y los municipios, teniendo en cuenta la función articuladora departamental" (literal b). Las orientaciones son definidas como "instrucciones para el desarrollo de las directrices, con el objetivo de permitir una mejor comprensión e interpretación técnico jurídica, para facilitar su aplicación y desarrollo" (literal g). La política remite a "un proceso integrador de decisiones, acciones, acuerdos e instrumentos, encaminado a solucionar o a prevenir una situación definida como problemática, adelantado por autoridades públicas con la participación de los actores y sectores interesados" (literal i).

84 Corte Constitucional, sentencia C-535 de 1996.

85 Ibíd. En la sentencia C-149 de 2010, de manera gráfica, la Corte Constitucional plantea que una doble aproximación al contenido de este principio: "Desde una perspectiva positiva significa que la intervención el Estado, y la correspondiente atribución de competencias, debe realizarse en el nivel más próximo al ciudadano, lo cual es expresión del principio democrático y un criterio de racionalización administrativa, en la medida en que son esas autoridades las que mejor conocen los requerimientos ciudadanos. A su vez, en su dimensión negativa, el principio de subsidiariedad significa que las autoridades de mayor nivel de centralización sólo pueden intervenir en los asuntos propios de las instancias inferiores cuando éstas se muestren incapaces o sean ineficientes para llevar a cabo sus responsabilidades". 
departamentos y las implicaciones del principio de subsidiariedad, corresponde al POD. Este criterio resulta válido en tanto proporciona un elemento capaz de indicar (en positivo) el sentido de la encomienda realizada por la LOOT a los departamentos: a partir de la realidad territorial que se advierte a este nivel administrativo, los POD deben fijar líneas de decisión que orienten la planificación municipal, permitan acoplar sus determinaciones con intereses supralocales y optimizar el proceso de OT, cuidando siempre el respeto a márgenes que admitan su desarrollo por parte de las municipalidades, en atención a las exigencias que eleva el principio de autonomía territorial en este campo. Como ha sido señalado con acierto por la СОT, la finalidad que el artículo 29.2 de la LOOT señala a esta atribución departamental apunta a:

determinar escenarios de uso y ocupación del espacio, pero de ninguna manera regularlos, es decir, no se trata de una competencia compartida con el municipio, sino complementaria, por ende, su ejercicio comporta la adopción de directrices consistentes en la identificación de aquellos aspectos que a juicio del Departamento, son relevantes para el desarrollo armónico de su territorio, siempre y cuando estén referidos al potencial óptimo del ambiente y en función de los objetivos de desarrollo, potencialidades y limitantes biofísicos, económicos y culturales del Departamento. Una vez formuladas las directrices por parte del Departamento, los municipios del mismo o de la porción del territorio a la cual se refieren, deben desarrollarlos en sus respectivos instrumentos de ordenamiento territorial, en ejercicio de las funciones que les son propias en virtud de lo previsto en el numeral 7 del artículo 313 de la Carta Política.

De acuerdo con lo anterior, el ordenamiento territorial que deben definir los departamentos, a diferencia de los РОТ municipales, no administra el desarrollo físico del territorio y la utilización del suelo, el foco de las competencias es establecer los grandes acuerdos para el desarrollo territorial del departamento, diseñar las líneas estratégicas de trabajo conjunto con los municipios, promover procesos de desarrollo territorial articulados, orientar los procesos de ordenamiento territorial supramunicipal e impulsar actuaciones de interés departamental o supramunicipal, gestionando además los proyectos de impacto regional, que beneficien a más de un municipio de su jurisdicción ${ }^{80}$ (cursivas fuera de texto).

Se trata, por tanto, de una competencia materialmente distinta de la que reconocen la Constitución y la ley a los municipios con la expedición de los POT: tanto por su objeto directo, que no es la reglamentación de los usos del suelo o la adopción de otras determinaciones con incidencia inmediata y directa sobre el desarrollo urbano (clasificación de los suelos, intensidades de usos, tratamientos, normas urbanas, etc.), sino la definición de directrices y orientaciones para que los municipios cumplan su papel de una forma más conforme a los requerimientos de la sostenibilidad, el desarrollo, la eficiencia, la competitividad, la equidad, la seguridad y la cohesión del territorio departamental, 
como por su finalidad, que es esencialmente de intermediación y articulación de los requerimientos supralocales y las determinaciones de la política nacional de OT con las decisiones de ordenación urbanística del territorio a cargo del municipio. En este orden, antes que en una inconveniente situación de permanente conflicto o tensión (por tratarse de competencias materiales afines, sin fronteras nítidas que las separen), las relaciones entre los POT y los POD deben ser de armoniosa concurrencia, coordinación y complementariedad ${ }^{87}$. Ello presupone, no obstante, una delimitación legal adecuada de los ámbitos de competencia de cada una de estas instancias. De lo contrario, el riesgo de colisión o conflicto se mantendrá latente.

Como se puede apreciar, si bien es cierto que existen amenazas serias para la autonomía municipal en el ejercicio de su competencia de ordenación urbanística del territorio, también lo es que una regulación legal apropiada de esta materia podría contribuir decisivamente a neutralizar estos peligros y a optimizar la coexistencia de instrumentos de OT de diferentes niveles y con distintos enfoques y roles. Con todo, es preciso que ello sea objeto de una regulación adecuada por parte del legislador. La promulgación de una ley que se ocupe de este asunto y defina reglas que hagan posible disipar los riesgos que entraña la expedición de los POD (en las condiciones normativas actuales) para la autonomía local constitucionalmente garantizada y maximizar las ventajas de su reciente creación, es, pues, una necesidad apremiante.

Finalmente, debe también repararse en que por razones muy similares a las expuestas respecto de la autonomía local, la ausencia de un procedimiento legalmente establecido dificulta la materialización del principio y el derecho de participación en una decisión que, como ha sido definido por la jurisprudencia constitucional, presupone y exige altos niveles de participación ciudadana ${ }^{88}$. $\mathrm{Si}$, como afirma Beuf, "ordenar es ante todo construir territorios" ${ }^{\prime 89}$, parece inconcebible un ejercicio de OT al margen de la ciudadanía. Ello resulta crucial, no solo para desarrollar el principio de participación ciudadana proclamado por el artículo 1 de la Constitución y hacer operativos los mandatos contenidos en sus artículo 2 y 79, de acuerdo con los cuales es fin esencial de las autoridades "facilitar la participación de todos en las decisiones que los afectan y en la vida económica, política, administrativa y cultural de la Nación", y corresponde al Estado, respecto del medio ambiente, garantizar "la participación de la

87 Este ha sido el enfoque que la jurisprudencia administrativa ha definido para las relaciones muy similares a las que ahora se examinan, entre POT y planes integrales de desarrollo metropolitano, a cargo de las áreas metropolitanas. Al respecto, véase JuAn CARLOS CoviLLA MARTínEZ, Las administraciones metropolitanas, Bogotá: Externado de Colombia, 2010, pp. 120 y ss.

88 Cfr. Corte Constitucional, sentencia T-537 de 2013. También la sentencia T-445 de 2016 de esta misma Corporación.

89 Alice Beuf, op. cit., p. 13 
comunidad en las decisiones que puedan afectarlo". Es clave, además, para asegurar mayores posibilidades de acierto y efectividad de las medidas adoptadas (las cuales no solo no deben generar el rechazo o la oposición de la comunidad, sino que idealmente deben expresar sus aspiraciones y atender sus necesidades), así como para garantizar la legitimidad política de las determinaciones de la OT; algo vital en un instrumento con vocación de estabilidad, pretensión de ordenar un territorio por un término considerable y con una fuerte incidencia sobre decisiones de otras instancias administrativas (municipales), que verán recortada su autonomía en relación con un aspecto esencial de su vida local. La estructuración legal de procedimientos claros, completos y adecuados para cristalizar el principio y el derecho a la participación ciudadana resulta, así, imperativa ${ }^{90}$. De lo contrario, librado a la voluntad de las autoridades públicas, tristemente, el principio/derecho de participación se encuentra en serio riesgo de ser ignorado, minusvalorado y vulnerado.

\section{CONSIDERACIONES FINALES}

Como ha quedado en evidencia en las líneas anteriores, el panorama de la OT en Colombia no está despejado. Pese a las auspiciosas posibilidades para un desarrollo óptimo de esta función y un mejor cumplimiento de sus fines que brinda el instrumento de los POD, las sombras que se proyectan sobre su adopción como consecuencia de la ausencia de un régimen legal adecuado, que se preocupe por delinear con claridad y rigor los perfiles de esta nueva figura, nublan el horizonte y dan pie para objeciones serias, que no pueden ser pasadas por alto. Ni el principio de legalidad, ni la autonomía territorial, ni la participación ciudadana en esta materia son cuestiones menores. De aquí que en cierta forma sorprenda la inadvertencia con que hasta el momento parecen haberse tratado.

Aunque poco debatida, la decisión de la Corte Constitucional de declarar la inexequibilidad del artículo 7 de la LDU al poco tiempo de su entrada en vigencia, terminó por impactar de manera profunda sobre el esquema de OT en Colombia. Al expulsar del ordenamiento jurídico la norma legal que establecía las competencias que en este campo se reconocían a la nación y los departamentos, restringió el papel de estos niveles administrativos supramunicipales en la materia y, quizás sin reparar en sus implicaciones, entregó todo el protagonismo a los entes locales.

90 En definitiva, como señala Cassese, "Para permitir la participación, se necesitan normas de procedimiento detalladas". De aquí que, como observa este autor, en atención a la importancia creciente de este principio dentro de las decisiones que adopta la Administración en nuestro tiempo, "la regulación administrativa consiste, cada vez más, en la regulación de procedimientos". SABINO CASSESE, Derecho administrativo. Historia y futuro, Madrid: INAP Editorial Derecho Global, Sevilla, 2014, p. 451. 
Así se ha desarrollado hasta ahora la OT en nuestro país. Y aun cuando ello ha rendido frutos positivos indiscutibles, por las disfunciones que comporta, se trata de una situación que es importante corregir. Como sugiere la LOOT, la capacidad de articulación y planificación territorial del nivel intermedio puede resultar útil a este propósito. Los retos sociales, económicos, ecológicos y políticos que afrontan los departamentos y el Estado colombiano en su conjunto parecen acentuar esta necesidad y urgir la consolidación de un modelo de planificación territorial más sostenible, eficiente, equitativo y moderno. No obstante, ello no se puede hacer de cualquier manera. Este importante paso debe darse con apego a las exigencias que nuestra Constitución define tanto en materia de legalidad de las acciones administrativas, como de respeto pleno por la autonomía local y la participación ciudadana, como pilares sobre los que se ha erigido la OT en Colombia. Es preciso contar con un régimen legal adecuado que fije con rango de ley y para todo el territorio nacional las reglas fundamentales que deben gobernar y orientar el ejercicio de esta importante competencia de los entes departamentales. Los recientes escándalos de corrupción administrativa en el manejo de las competencias locales de ordenación urbanística, los permanentes enfrentamientos entre los municipios y la nación por la cuestión minera, y las recurrentes protestas de la ciudadanía por la ausencia de espacios efectivos para tomar parte activa en estos debates son la mejor prueba de esta necesidad. El legislador, órgano constitucionalmente a cargo de estas determinaciones, y el Gobierno, principal impulsor de las decisiones legislativas en nuestro país y gran responsable de la política de OT nacional, tienen la palabra.

\section{TABLA DE ACRÓNIMOS}

CEI Comisión Especial Interinstitucional

COT Comisión de Ordenamiento Territorial

DNP Departamento Administrativo Nacional de Planeación

LDU Ley 388 de 1997

LOOT Ley Orgánica de Ordenamiento Territorial (Ley 1454 de 2011)

от Ordenación del territorio

POD Plan de Ordenamiento Territorial Departamental

POT Plan de Ordenamiento Territorial Municipal o Distrital

UPR Unidad de Planificación Rural

\section{BIBLIOGRAFÍA}

Agudelo Patiño, Luis Carlos. La ciudad sostenible. Dependencia ecológica y relaciones regionales. Un estudio de caso en el área metropolitana de Medellín, Medellín: Universidad Nacional de Colombia, Sede Medellín, 2010. 
Agudo GonZÁLEZ, Jorge. "La formalización jurídico administrativa de la ordenación del territorio en España", Teoría y práctica para una ordenación racional del territorio, Madrid: Síntesis, 2010.

Arbouin Gómez, Felipe. "Derecho urbanístico y desarrollo territorial colombiano. Evolución desde la colonia hasta nuestros días", Revista Universitas, n. ${ }^{\circ} 124,2012$, pp. 38-39.

Baño León, José María. Derecho urbanístico común, Madrid: Iustel, 2009.

Bejarano Ramos, Constanza. "Funciones ambientales de los departamentos en Colombia", en Lecturas sobre derecho del medio ambiente, t. XVI, Bogotá: Universidad Externado de Colombia, 2016.

Beuf, Alice. "El concepto de territorio: de las ambigüedades semánticas a las tensiones sociales y políticas", en Ordenar los territorios. Perspectivas críticas desde América Latina, Alice Beuf y Patricia Rincón (eds.), Bogotá: Universidad Nacional de Colombia Universidad de Los Andes - Instituto Francés de Estudios Andinos, 2017.

Cassese, Sabino. Derecho administrativo. Historia y futuro, Madrid: INAP - Editorial Derecho Global, 2014.

Covilla MartíneZ, Juan Carlos. Las administraciones metropolitanas, Bogotá: Universidad Externado de Colombia, 2010.

Del Castillo Daza, Juan Carlos. "Ordenamiento territorial y ordenamiento ambiental", en Problemática jurídico-ambiental de los centros urbanos, Bogotá: Universidad Externado de Colombia, 2002.

Departamento Administrativo Nacional de Planeación. Elementos para la formulación de la política nacional de ordenamiento territorial y alcances de las directrices departamentales, Bogotá, 2013. Disponible en línea https://colaboracion.dnp.gov.co/CDT/Desarrollo\%20Territorial/Documento\%20PNOT-LOOT.\%20DDTS\%20-\%20SODT.\%20 11\%20junio\%20013.pdf.

Departamento Administrativo Nacional de Planeación. Balance sobre los avances en el diseño e implementación de lineamientos de ordenamiento territorial departamental que ban sido llevados a cabo en el país, Bogotá, 2013. Disponible en línea https://colaboracion. dnp.gov.co/CDT/Desarrollo\%20Territorial/Balance\%20procesos\%20de\%20Ordenamiento\%20Territorial\%20Departamental.pdf.

Departamento Administrativo de Planeación Territorial. Notas sobre el ordenamiento territorial y los proyectos de ley orgánica de ordenamiento territorial (Documento de Trabajo), 2007. 
Duque Cante, Naidú. "Particularidades de la Ley Orgánica de Ordenamiento Territorial", Análisis Político, vol. 25, n. ${ }^{\circ} 76,2012$. Disponible en línea https://revistas. unal.edu.co/index.php/anpol/article/view/43501/44784.

Estupiñán ACHury, LiLiana. Desequilibrios territoriales. Estudio sobre la descentralización y el ordenamiento territorial colombiano. Una mirada desde el nivel intermedio de Gobierno, Bogotá: Doctrina y Ley - Universidad del Rosario, 2012.

Fernández-Miranda Fernández-Miranda, Jorge. "El principio de legalidad, la vinculación negativa y el ejercicio de la potestad reglamentaria local", RAP, n. ${ }^{\circ}$ 196, 2015.

Galán Galán, Alfredo. "La consolidación del principio de vinculación negativa en el ámbito local", Revista Cemci, n. ${ }^{\circ} 8,2010$. Disponible en línea https://revista. cemci.org/numero-8/pdf/articulo2.pdf.

Galiana, Luis y Julio Vinuesa. "Definición y evolución del concepto y de su práctica", en Teoría y práctica para una ordenación racional del territorio, Madrid: Editorial Síntesis, 2010.

Gómez Orea, Domingo. Ordenación territorial, Madrid: Ediciones Mundi-Prensa - Editorial Agrícola Española, 2002.

González DíAZ, Andrés. "Los departamentos y sus funciones ambientales dentro del SINA", en Sistema Nacional Ambiental, 15 años. Evaluación y perspectivas, Bogotá: Universidad Externado de Colombia, 2008.

Guinard Hernández, David. "La regulación económica como instrumento de dirección estatal de la economía". Revista digital de Derecho Administrativo, n. . 18, 2017.

Hernández Betancur, Luis Fernando. "Planificación territorial para el desarrollo sostenible", en Lecturas sobre derecho del medio ambiente, t. XII, Bogotá: Universidad Externado de Colombia, 2012.

Hildebrand SCHEID, ANDREAS. "Tres propuestas para una relación efectiva entre las escalas regional y local en materia de ordenación del territorio", en Territorialidad y buen gobierno para el desarrollo sostenible, Valencia: Universidad de Valencia, 2007.

Hildebrand Scheid, Andreas. "La política de ordenación del territorio de las comunidades autónomas: balance crítico y propuestas para la mejora de su eficacia", Revista de Derecho Urbanístico y Medio Ambiente, n. ${ }^{\circ}$ 230, 2006. Disponible en línea http://hum117.uca.es/grupogial/paginas/docencia/otymadoc/hildembrand.

Instituto De Estudios Urbanos. "Planes de Ordenamiento Territorial Departamental frente a los Municipios", Debates de Gobierno Urbano, n. ${ }^{\circ}$ 8, 2016.

LÓPEZ RAMÓn, FERNANDO, Introducción al derecho urbanístico, 4. a edición, Madrid: Marcial Pons, 2013. 
Maldonado Copello, María Mercedes. "El proceso de construcción del sistema urbanístico colombiano: entre reforma urbana y ordenamiento territorial", Direito Urbanístico. Estudos brasileiros e internacionais, Belo Horizonte: Editora Del Rey - Lincoln Institute of Land Policy, 2006.

Mariño Drews, Juana. "Territorio... ¿Cuál territorio? Elementos para una investigación", en Evaluación y perspectivas del Código Nacional de Recursos Naturales de Colombia en sus 30 años de vigencia, Bogotá: Universidad Externado de Colombia, 2004.

Massiris Cabezas, Ángel, "Políticas latinoamericanas de ordenamiento territorial. Realidad y desafíos", en AA.vV., Procesos de ordenamiento en América Latina y Colombia, Bogotá: Universidad Nacional de Colombia, 2012.

Ministerio de Vivienda, Ciudad y Territorio. Bases conceptuales para la formulación del ordenamiento territorial departamental en el marco de la LOOT/ Ley 1454 de 2011 (Documento preliminar), Bogotá, 2012. Disponible en línea https://colaboracion.dnp.gov. co/CDT/Desarrollo\%20Territorial/Bases\%20conceptuales\%20para\%201a\%20 formulaci\%C3\%B3n\%20del\%20ordenamiento\%20territorial\%20departamental\%20-\%20mVCT.pdf.

Morcillo Dosman, Pedro Pablo. Derecho urbanístico colombiano. Historia, derecho y gestión, Bogotá: Temis, 2007.

Parejo Alfonso, Luciano. "La ordenación territorial y urbanísticas y el gobierno de la ciudad en el estado territorialmente descentralizado", Revista digital de Derecho Administrativo, $\mathrm{n}^{\circ} .7,2012$.

Parejo Alfonso, Luciano. Lecciones de derecho administrativo, 3. a edición, Bogotá: Tirant lo Blanch - Universidad Externado de Colombia, 2011.

Rincón CóRdoba, Jorge IvÁn. Planes de ordenamiento territorial, propiedad y medio ambiente, Bogotá: Universidad Externado de Colombia, 2012.

Robledo Silva, Paula. "Los principios de coordinación, concurrencia y subsidiariedad: una posible solución a la problemática del reparto de competencias en materia minera", en Minería y desarrollo. Historia y gobierno del territorio minero, Juan Carlos Henao y Sebastián Ángel (eds.), t. 5, Bogotá: Universidad Externado de Colombia, 2016.

Robledo Silva, Paula. "La Ley Orgánica de Ordenamiento Territorial: ¿una asignatura pendiente?", en Derecho procesal administrativo, modernización del Estado y territorio. Estudios en bomenaje a Augusto Hernández Becerra, Bogotá: Ibáñez, 2014.

Rodríguez de SANTIAGo, José María. Metodología del derecho administrativo. Reglas de racionalidad para la adopción y el control de la decisión administrativa, Madrid: Marcial Pons, 2016.

Rodríguez de Santiago, José María. La ponderación de bienes e intereses en el Derecho administrativo, Madrid - Barcelona: Marcial Pons, 2000. 
Santaella Quintero, Héctor. "Un territorio y tres modelos de gestión: análisis de la necesidad de armonizar y constitucionalizar las competencias urbanísticas, ambientales y mineras sobre el territorio", Minería y desarrollo. Historia y gobierno del territorio minero, Juan Carlos Henao y Sebastián Ángel (eds.), t. 5, Bogotá: Universidad Externado de Colombia, 2016.

Santaella Quintero, Héctor. "Urbanismo y minería: tensiones y conflictos sobre los usos del suelo en el territorio municipal", Revista de Derecho Administrativo Económico, n. ${ }^{\circ} 19,2014$.

Santaella Quintero, Héctor. "El autogobierno del territorio: ¿Un contenido esencial de la autonomía territorial?", en Derecho procesal administrativo, modernización del Estado y territorio. Estudios en bomenaje a Augusto Hernández Becerra, Bogotá: Ibáñez, 2014.

Santaella Quintero, Héctor. "Del principio de legalidad al principio de juridicidad: implicaciones para la potestad normativa de la administración de una transición constitucionalmente impuesta", La Constitucionalización del Derecho Administrativo. XV Jornadas Internacionales de Derecho Administrativo, Bogotá: Universidad Externado de Colombia, 2014I

Santofimio Gamboa, Jaime Orlando. "Estudio introductorio. Características del Derecho urbanístico colombiano", en Derecho urbanístico. Legislación y jurisprudencia, Bogotá: Universidad Externado de Colombia, 2004.

SChmidt-Assmann, EBerhard, La teoría general del derecho administrativo como sistema, Madrid - Barcelona: Marcial Pons, 2003.

Secretaria Técnica de la cot, Comité EsPeCial Interinstitucional. Lineamientos para el proceso de ordenamiento territorial departamental. Contenidos básicos, Bogotá, DNP. Disponible en línea https://www.usbcali.edu.co/sites/default/files/lineamientosdelacot.pdf.

Suelt Cock, VAnessa. "Un nuevo paradigma del estado unitario: la asimetría territorial y los esquemas de coordinación", Universitas, n. ${ }^{\circ}$ 127, 2013.

Vélez Restrepo, Luis Aníbal. "La perspectiva ambiental en el plan de ordenamiento territorial del municipio", en Los planes de ordenamiento territorial municipal en Antioquia, Medellín: Universidad Nacional de Colombia, 2013. 